\title{
Review of Most Important Biomedical Databases for Searching of Biomedical Scientific Literature
}

\author{
Izet Masic
}

\section{ABSTRACT}

We are living in the time of displossion of medical scientific information. Only in PubMed/MedLine, one of the largest host of scientific biomedical literature is indexed in almost 5,000 scientific biomedical journals. Each scientific paper is recorded in data written by rules recommended by several scientific associations and institutions. Databases can contain information about the author(s) and his/their published scientific works or results of research/investigation, including bibliographic data, abstract or full text of the paper. The databases are collecting and processing the best scientific and professional papers, or reviews and case reports published in scientific and professional journals or other publications. The reliability and quality of information guarantees producers of databases. Most important databases are located in famous university/academic centers like Bethesda [National Library Medicine (NLM)], Philadelphia (ISI), Amsterdam (Elsevier), Ipswitch (EBSCO), G eneva (WHO), Moscow (RAS), Shiraz [Islamic World Science Citation Center (ISC)], Warsaw [Index Copernicus (IC)]. Author of this review article shortly described most important online databases of biomedical literature today which will be usefull for scientists or other medical professionals.

Keywords: Scientific information, Online databases.

How to cite this article: Masic I. R eview of Most Important Biomedical Databases for Searching of Biomedical Scientific Literature. Donald School J Ultrasound Obstet Gynecol 2012;6(4):343-361.

\section{Source of support $\mathrm{Nil}$}

Conflict of interest: None declared

\section{GENERALLY ABOUT BIOMEDICAL ONLINE DATABASES}

The database system is an organized set of data. It consists of records, identically defined and desribed. Each scientific paper is recorded in data written by rules recommended by several scientific associations and committees. ${ }^{1-13}$ Databases can contain information about the author (including bibliographic data and abstract) and the original work. Data set determines the type of base as: (a) bibliographic databases, (b) citation databases, (c) full-text databases. M ost important databases are located in famous university/ academic centers like B ethesda (NL M ), Philadelphia (ISI), A msterdam (Elsevier), I pswitch (EBSCO), Geneva (W HO), M oscow (RAS), Shiraz (ISC), W arsaw (IC), etc. ${ }^{14-30}$ For all the databases, there is same basic information: Author (by name); title; magazine which is published and year of publication. ${ }^{1}$

Generally, we can divide them into three categories: ${ }^{1,2}$

\section{A. Bibliographic Databases}

Contents bibliographic database refers to papers published in various journals and publications. They contain information such as author, title, source, abstract, year of publication, the institution from which the author comes, publication type, the original language of bibliographic databases, etc. Bibliographic database can vary depending on the area, scope and structure of bibliographic records that enable, a description of the works are very detailed and uniform. These databases are linked with other databases and the original version of published works. ${ }^{1}$

\section{B. Citation Databases}

Citation databases are also bibliographic databases. Since, bibliographic databases differ in addition to the work themselves, processed and used references, the above quote by the author, at the end of work. W ith them we learn how the works are quoted and used to assess the quality of the cited work and estimated the impact of individual works by specifying the number of citations. ${ }^{1}$

\section{Full-text Databases}

These are mainly collections of journals in electronic form, one or more publishers. It contains bibliographic information (as well as bibliographic databases) and numerous other data. It should be alert to the difference between databases with full text to the bibliographic, which have only indicated a connection (link) with the full-text bases. Full-text databases usually offered in HTM L and/or PDF format. ${ }^{1}$

\section{THOMSON REUTERS}

Thomson Reuters Corporation (NY SE: TRI) is a business data provider and was created by the Thomson Corporation's purchase of Reuters Group on 17 A pril 2008 (Figs 1 and 2). ${ }^{13-15}$ The Thomson Corporation acquired Reuters

N ote: This article is a little shorter and corrected version of previously published article in the journal A cta Informat M ed 2012;20(2):72-84. With permission of the author it could be published in the D onald School J ournal of U Itrasound in Obstetrics and Gynecology. 


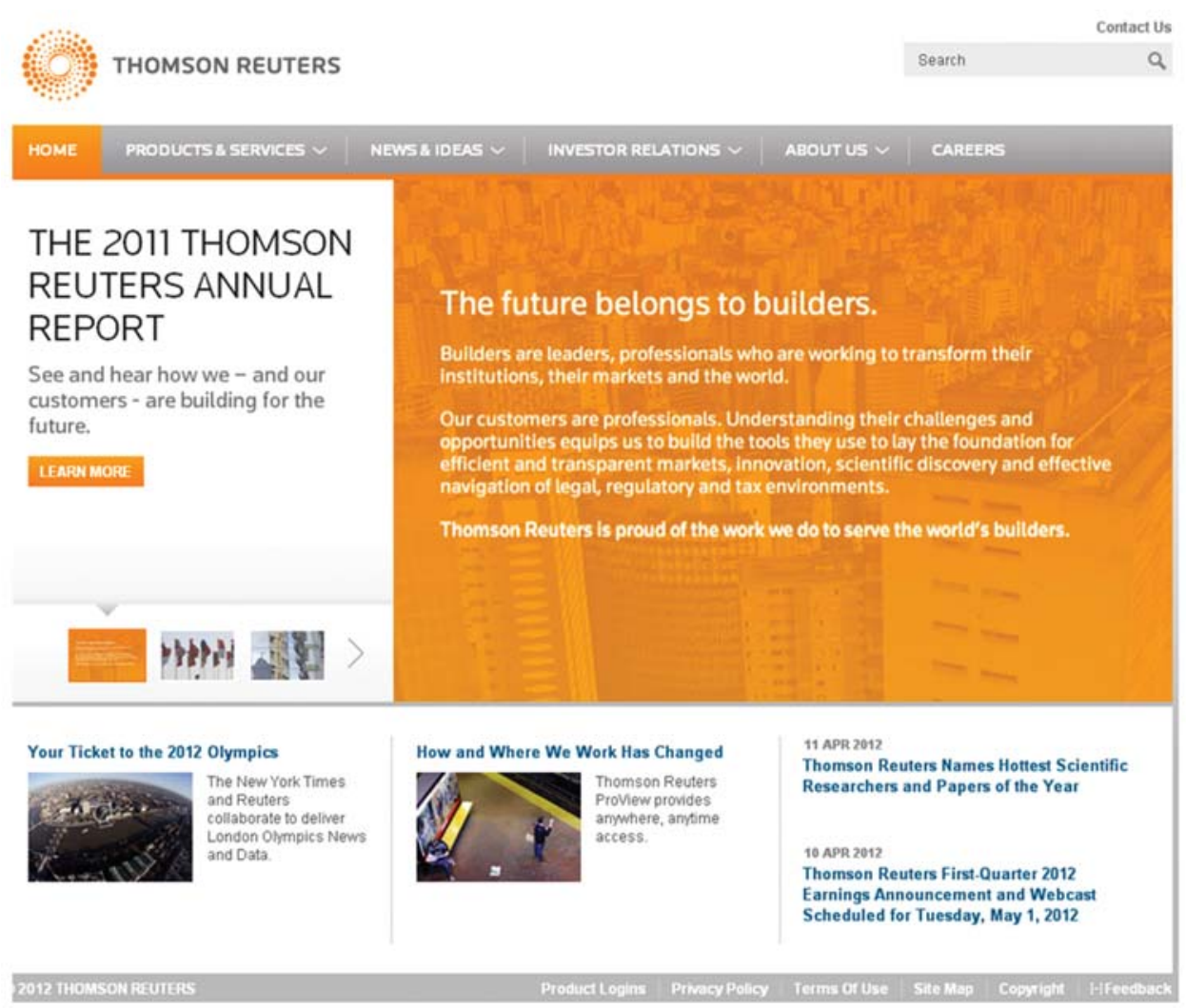

Fig. 1: Source: http://thomsonreuters.com/products_services/science/science_products/a-z/current_contents/. Accessed April 12,2012

Group PLC to form Thomson Reuters on A pril 17, 2008. Thomson Reuters operated under a dual-listed company (DLC) structure and had two parent companies, both of which were publicly listed- -Thomson Reuters Corporation and Thomson R euters PLC. The company is organized into two divisions:

\section{Markets Division}

- Financial professionals and marketplaces

- Enterprise solutions,

- Media.

\section{Professional Division}

- Legal - -formerly N orth A merican L egal and R egulatory A ffairs Committee; including W est, makers of W estlaw and Carswell

- IP and Science--formerly Thomson Healthcare and Thomson Scientific

- Tax and Accounting - -formerly Thomson Tax and Accounting.

\section{Current Contents}

Current Contents ${ }^{\circledR}$ is a current awareness database that provides easy access to complete tables of contents, bibliographic information and abstracts from the most recently published issues of leading scholarly journals. ${ }^{13,14}$

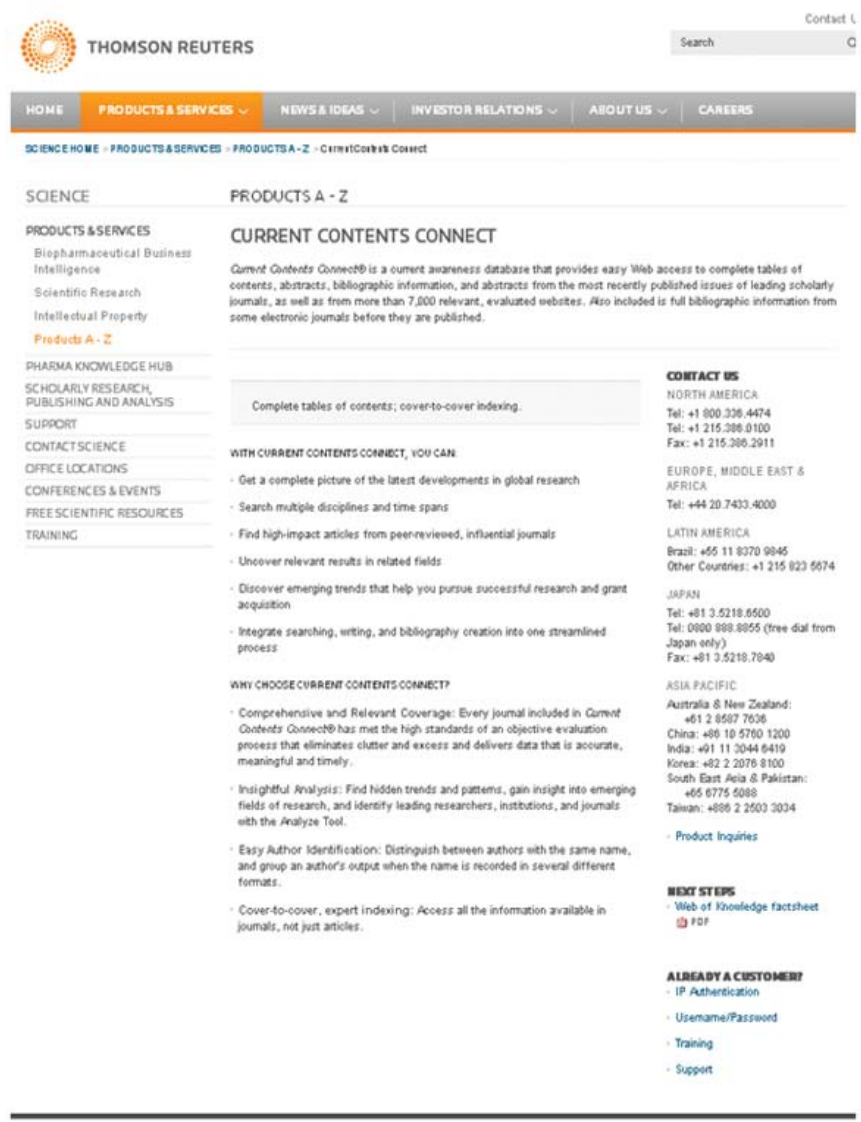

Fig. 2: Source: http://thomsonreuters.com/products_services/ science/science_products/a-z/current_contents_connect/. Accessed April 12, 2012 
Cover-to-cover, expert indexing provides accurate access to all the information available in journals, not just articles.

The web version, Current Contents Connect ${ }^{\circledR}$, is part of the $\mathrm{W}$ eb of $\mathrm{K}$ nowledge integrated solution and offers daily updates and data from evaluated web sites and documents.

Current contents was first published in paper format, in a single edition devoted only to biology and medicine. Other subject editions were added later. Initially, it consisted simply of a reproduction of the title pages from several hundred major peer-reviewed scientific journals, and was published weekly, with the issues containing title pages from journal issues only a few weeks previously, a shorter time lag than any service then available. There was an author index and a crude keyword subject index only. A uthor addresses were provided so readers could send reprint requests for copies of the actual articles.

Still published in print, it is presently available as one of the databases included in Thomson's ISI Web of Knowledge with daily updates and also through other database aggregators.

The following different editions exist are:

- Current Contents Agricultural, Biological and Environmental Sciences

- Current Contents A rts and Humanities

- Current Contents Clinical Practice

- Current Contents Engineering, Technology and A pplied Sciences

- Current Contents Life Sciences

- Current Contents Physical Chemical and Earth Sciences

- Current Contents Social and Behavioral Sciences.

\section{ISI Web of Knowledge}

Thomson Reuters Web of $\mathrm{K}$ nowledge $\mathrm{SM}^{\mathrm{SM}}$ is a research platform that gives you access to objective content and powerful tools to search, track, measure and collaborate in the sciences, social sciences, arts and humanities (Fig. 3). ${ }^{13,15}$ This intelligent research platform provides access to the world's leading citation databases, including powerful cited reference searching, the A nalyze Tool, and over 100 years of comprehensive backfile and citation data.

With Thomson Reuters W eb of K nowledge, you can choose the resources that you need--there's no need to subscribe to unnecessary or extraneous databases. ${ }^{13,16}$ Combine renowned multidisciplinary databases with content-specific selections and tools for analysis and measurement to create the W eb of Knowledge that turns raw data into the powerful knowledge you need.

Citations symbolize the association of scientific ideas. W eb of K nowledge uniquely indexes both cited and citing works, which enables the user to make explicit links between current research and prior scientific works.

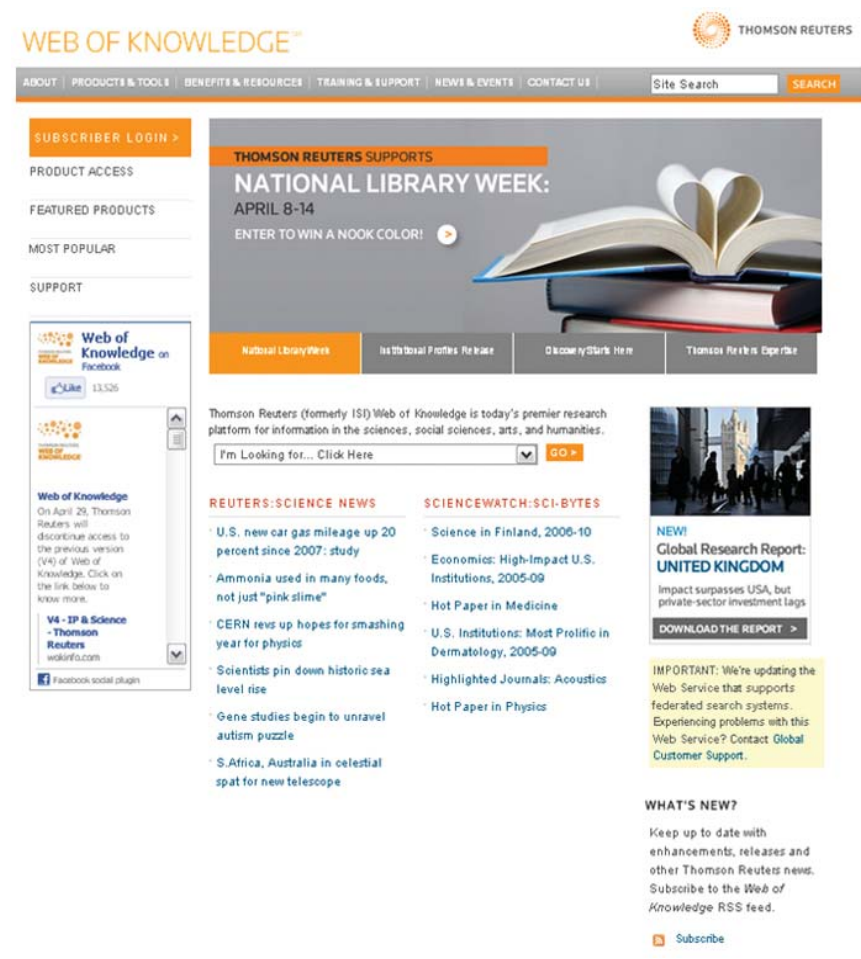

Fig. 3: Source: http://wokinfo.com/about/whatitis/. Accessed April 12, 2012

Use cited reference data to move both backward and forward in time to track and determine research influence.

U se citation analysis to find influential authors who are publishing high-impact research in your field, discover important author and/or institutional research collaborations, determine where the most impactful research is being published.

A nalyze research from high-impact journals in the sciences, social sciences, arts and humanities, and seaml essly link to full-text articles.

It is described as a unifying research tool which enables the user to acquire, analyze, and disseminate database information in a timely manner. This is accomplished because of the creation of a common vocabulary for varied search terms and varied data. M oreover, search terms generate related information across categories.

A cceptable content for the W eb of $\mathrm{K}$ nowledge is determined by an evaluation and selection process based on the following criteria: Impact, influence, timeliness, peer review and geographic representation.

The database includes the following:

- 23,000 academic and science journals (including W eb of Science (W OS) journal listings);

- 23,000,000 patents;

- 110,000 conference proceedings;

- 9000 websites;

- Coverage from theyear 1900 to present day (with W OS);

- Over 40 million source items;

- Integrated and simultaneous searching across multiple databases. 


\section{ISI Web of Science}

W eb of Science (W oS) is an online academic citation index provided by Thomson Reuters: It is designed for providing access to multiple databases, crossdisciplinary research, and in-depth exploration of specialized subfields within an academic or scientific discipline (Fig. 4). ${ }^{13,14}$ As a citation index, any cited paper will lead to any other literature (book, academic journal, proceedings, etc.) which currently, or in the past, cites this work. In addition, literature which shows the greatest impact in a field covered by WoS, or more than one discipline, can be selectively obtained. For example, a paper's influence can be determined by linking to all the papers that have cited it. In this way, current trends, patterns and emerging fields of research can be assessed. WoS has indexing coverage from the year 1900 to the present. WoS ${ }^{\circledR}$ provides researchers, administrators, faculty and students with quick, powerful access to the world's leading citation databases. A uthoritative, multidisciplinary content covers over 12,000 of the highest impact journals worldwide, including open access journals and over 150,000 conference proceedings. Y ou will find current and retrospective coverage in the sciences, social sciences, arts and humanities, with coverage to 1900 . Titles of foreign language publications are translated into English and so cannot be found by searches in the original language.

The following types of literature are indexed: Peerreviewed journals, original research articles, reviews, editorials, chronologies, abstracts, as well as other areas. Disciplines included in this index are agriculture, biological sciences, engineering, medical and life sciences, physical and chemical sciences, anthropology, law, library sciences, architecture, dance, music, film and theater. Six citation databases encompass coverage of the above disciplines.

\section{WoS has Six Available Databases}

- Science Citation Index expanded covers more than 7100 notable journals encompassing 150 disciplines. Coverage is from the year 1900 to the present day.

- Social Sciences Citation Index covers more than 2470 journals encompassing 50 social science disciplines. M oreover, this index covers 3,500 notable scientific and technical journals. Range of coverage is from the year 1956 to the present day.

- Arts and Humanities Citation Index covers more than 1395 arts and humanities journals, in addition to certain items from more than 6000 scientific and social sciences journals.

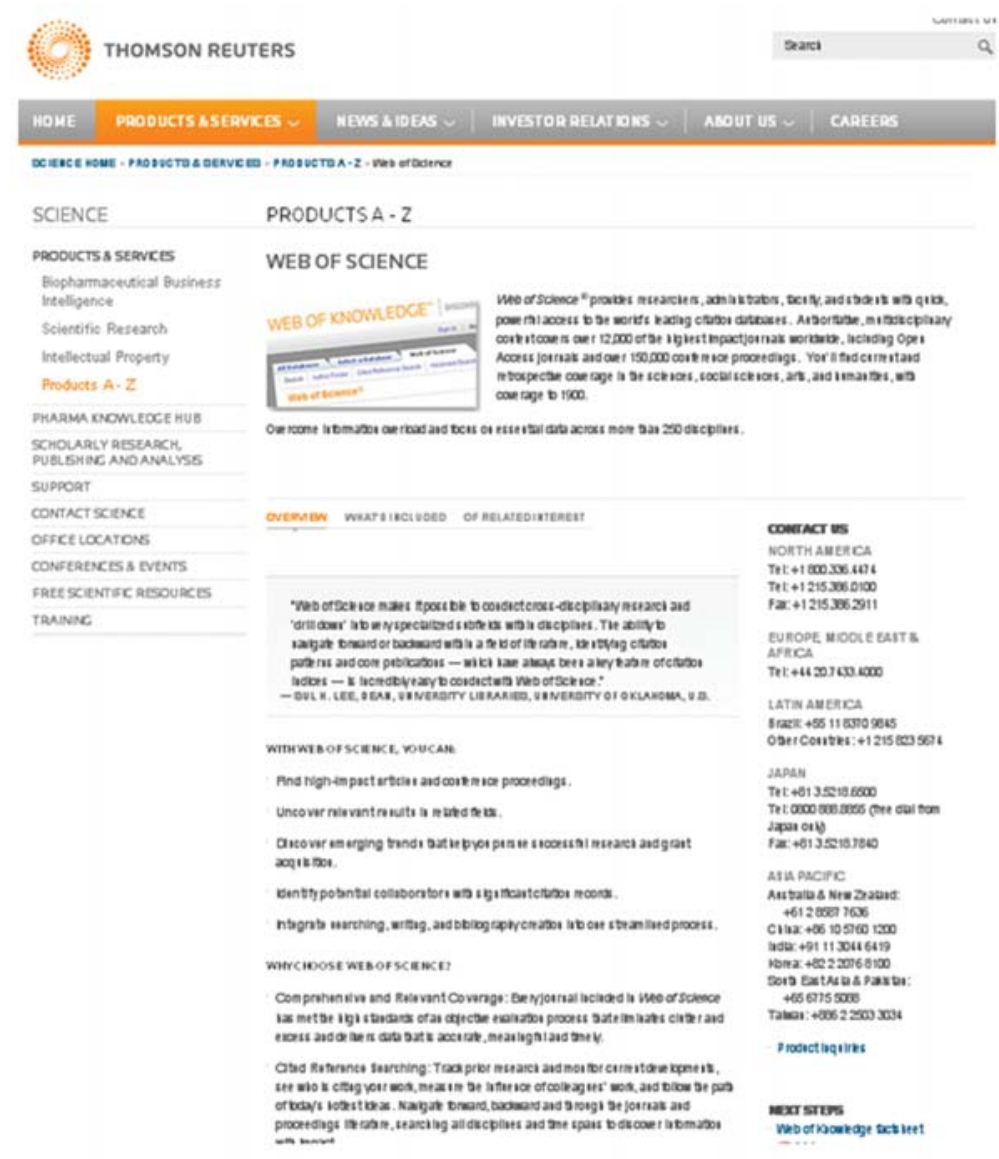

Fig. 4: Source: http://thomsonreuters.com/products_services/science/ science_products/a-z/web_of_science/. Accessed April 12, 2012 
- Conference Proceedings Citation Index covers more than 110,000 journals and book-based proceedings in two editions: Science and Social Science and Humanities, encompassing 256 disciplines.

- Index Chemicus indexes more than 2.6 million compounds. The range of coverage is from 1993 to present day.

- Current Chemical Reactions indexes over one million reactions, and the range of coverage is from 1986 to present day. The INPI archives from 1840 to 1985 are also indexed in this database.

\section{NLM-NATIONAL LIBRARY OF MEDICINE DATABASES}

The National Library of Medicine (NLM), in Bethesda, $M$ aryland, is a part of the $N$ ational Institutes of $\mathrm{H}$ ealth $(\mathrm{NIH})$, US Department of Health and Human Services (HHS) (Fig. 5). ${ }^{16-18}$ Since its founding in 1836, N L M has played a pivotal role in translating biomedical research into practice. It is the world's largest biomedical library and the developer of electronic information services that deliver trillions of bytes of data to millions of users every day. Scientists, health professionals and the public in the US and around the globe search the Library's online information resources more than one billion times each year.

The Library is open to all and has many services and resources--for scientists, health professionals, historians and the general public. NLM has nearly 12 million books, journals, manuscripts, audiovisuals and other forms of medical information on its shelves, making it the largest health-science library in the world.

In today's increasingly digital world, NLM carries out its mission of enabling biomedical research, supporting health care and public health and promoting healthy behavior by:

- Acquiring, organizing and preserving the world's scholarly biomedical literature.

- Providing access to biomedical and health information across the country in partnership with the 5,600-member N ational N etwork of Libraries of M edicine $\left(\mathrm{NN} / \mathrm{LM} \mathrm{M}^{\circledR}\right)$.

- Serving as a leading global resource for building, curating and providing sophisticated access to molecular biology and genomic information, including those from the Human Genome Project and NIH Roadmap.

- Creating high-quality information services relevant to toxicology and environmental health, health services research and public health.

- Conducting research and development on biomedical communications systems, methods, technologies and networks and information dissemination and utilization

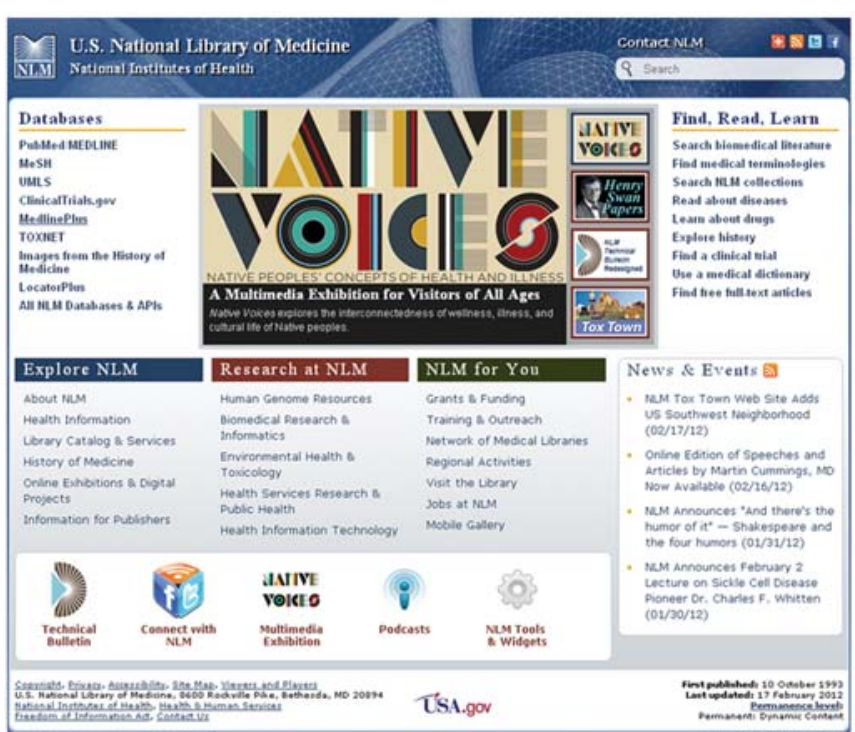

Fig. 5: Source: http://www.nlm.nih.gov/pubs/factsheets/nlm.html. Accessed April 12, 2012

among health professionals, patients and the general public.

- Funding advanced biomedical informatics research and serving as the primary supporter of pre- and postdoctoral research training in biomedical informatics at 18 US universities.

Scientific Information Services: The most frequently consulted online scientific medical resource in the world is MEDLINE ${ }^{\circledR} /$ PubM ed $^{\circledR}$, a publicly available database of over 18 million journal citations from 1948 to the present.

A nother important part of NLM 's vast online holdings is PubM ed Central ${ }^{\circledR}$ (PMC), a web-based repository of biomedical journal literature providing free, unrestricted access to more than 1.5 million full-text articles.

\section{PubMed/MEDLINE}

M EDL INE is the US NL M ${ }^{\circledR}$ premier bibliographic database that contains over 19 million references to journal articles in life sciences with a concentration on biomedicine (Fig. 6). ${ }^{16,17} \mathrm{~A}$ distinctive feature of MEDLINE is that the records are indexed with NLM M edical Subject Headings $\left(\mathrm{MeSH}^{\circledR}\right.$ ).

The great majority of journals are selected for M EDLINE based on the recommendation of the Literature Selection Technical Review Committee (LSTRC), an NIH-chartered advisory committee of external experts analogous to the committees that review NIH grant applications. Some additional journals and newsletters are selected based on NLM -initiated reviews, e.g. history of medicine, health services research, AIDS, toxicology and environmental health, molecular biology and complementary medicine, that are special priorities for NLM or other NIH components. 


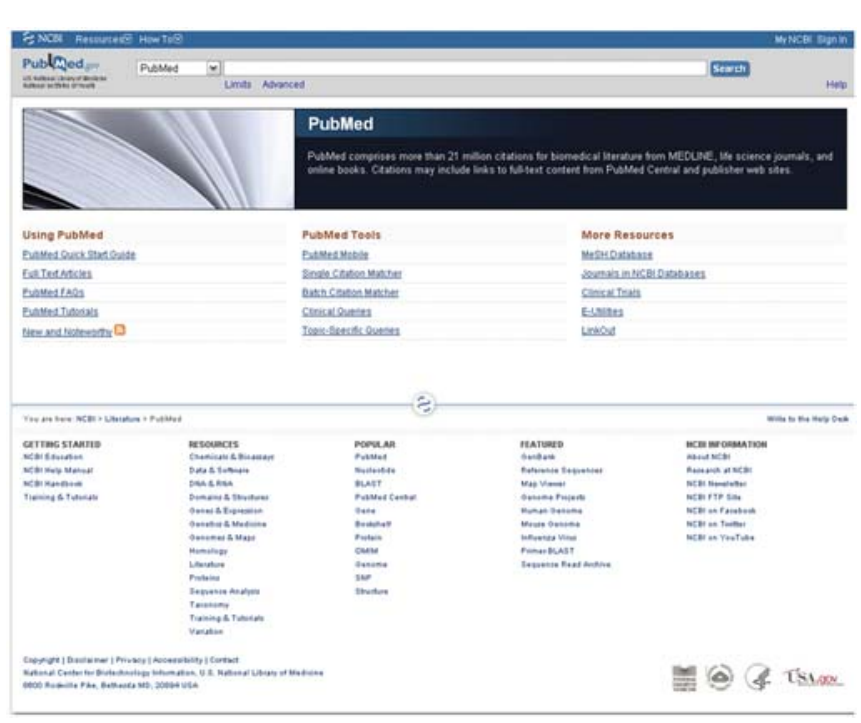

Fig. 6: Source: http://www.nlm.nih.gov/pubs/factsheets/ medline.html. Accessed April 12, 2012

These reviews generally also involve consultation with an array of NIH and outside experts or, in some cases, external organizations with which NLM has special collaborative arrangements.

MEDLINE is the primary component of PubM ed ${ }^{\circledR}$, part of the Entrez series of databases provided by the NLM $N$ ational Center for Biotechnology Information (NCBI). Time coverage: Generally 1946 to the present, with some older material.

Source: Currently, citations from approximately 5,600 worldwide journals in 39 languages; 60 languages for older journals. Citations for M EDL INE are created by the NLM, international partners and collaborating organizations.

U pdates: Since 2005, between 2,000 and 4,000 completed references are added each day, Tuesday through Saturday; nearly 700,000 total added in 2010. U pdates are suspended for several weeks during N ovember and December as N L M makes the transition to a new year of M eSH vocabulary used to index the articles.

Broad subject coverage: The subject scope of MEDLINE is biomedicine and health, broadly defined to encompass those areas of the life sciences, behavioral sciences, chemical sciences and bioengineering needed by health professionals and others engaged in basic research and clinical care, public health, health policy development or related educational activities. MEDLINE also covers life sciences vital to biomedical practitioners, researchers and educators, including aspects of biology, environmental science, marine biology, plant and animal science as well as biophysics and chemistry. Increased coverage of life sciences began in 2000 .

The majority of the publications covered in M EDLINE are scholarly journals; a small number of newspapers, magazines and newsletters considered useful to particular segments of the NLM broad user community are also included. For citations added from 2005 to 2009: about $45 \%$ are for cited articles published in the US, about $91 \%$ are published in English and about 83\% have English abstracts written by authors of the articles.

Availability: MEDLINE is the primary component of PubM ed (http://pubmed.gov ); a link to PubM ed is found on the NLM home page at http://www.nlm.nih.gov . The result of a MEDLINE/PubM ed search is a list of citations (including authors, title, source and often an abstract) to journal articles and an indication of free electronic full-text availability. Searching is free of charge and does not require registration.

A growing number of M EDLINE citations contain a link to the free full text of the article archived in $\mathrm{PMC}{ }^{\circledR}$ or to other sites. Y ou can also link from many MEDLINE references to the web site of the publisher or other full-text provider to request or view the full article, depending upon the publisher's access requirements. For articles not freely

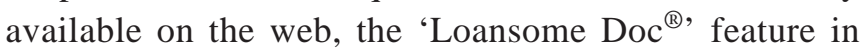
PubM ed provides an easy way to place an electronic order through the $\mathrm{N}$ ational $\mathrm{N}$ etwork of Libraries of Medicine ${ }^{\circledR}$ $\left(\mathrm{NN} / \mathrm{LM}^{\circledR}\right.$ ) for the full-text copy of an article cited in MEDLINE. Registration is required and local fees may apply for this service.

Services/products providing access to M EDLINE data are also developed and made available by organizations that lease the database from N L M . A ccess to various M EDL INE services is often available from medical libraries, many public libraries and commercial sources.

M edlinePlus ${ }^{\circledR}$, another service offered by the NLM , provides consumer-oriented health information. Health consumers are encouraged to discuss search results with their health care provider.

\section{PubMed Central}

PMC ${ }^{\circledR}$ is a free archive of biomedical and life sciences journal literature at the US National Institutes of Health's (NIH/N L M ; Fig. 7). ${ }^{16,18}$ In keeping with NL M 's legislative mandate to collect and preserve the biomedical literature, PMC serves as a digital counterpart to NLM 's extensive print journal collection. Launched in February 2000, PM C was developed and is managed by NLM 's NCBI.

As an archive, PMC is designed to provide permanent access to all of its content, even as technology evolves and current digital literature formats potentially become obsolete. NLM believes that the best way to ensure the accessibility and viability of digital material overtime is through consistent and active use of the archive. For this reason, free access to all of its journal literature is a core principle of PMC. 


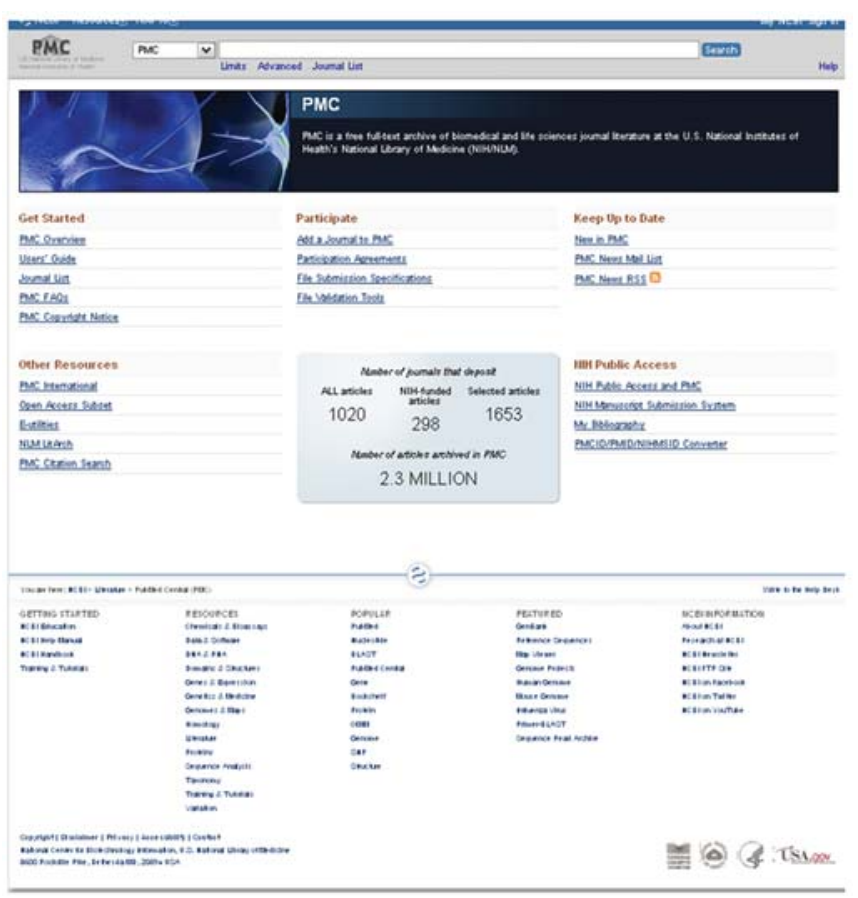

Fig. 7: Source: http://www.ncbi.nlm.nih.gov/pmc/about/intro/. Accessed April 12, 2012

The PM C N ational A dvisory Committee, established in 1999, provides independent advice on the content and operation of PMC. The Committee is responsible for establishing criteria for groups submitting material to the system and ensuring that PMC remains responsive to the needs of researchers, publishers, librarians and the general public. M embers of the Committee are appointed by the Director of the NIH from the biomedical and information communities as well as the general public.

PM C began operating in February 2000 with content from two journals: PNAS: Proceedings of the $\mathrm{National}$ A cademy of Sciences and M olecular B iology of the Cell.

The currency and age of material in PMC varies by journal. M any journals make their content available in PM C as soon as it is published. Others may delay release of content in PMC for anywhere from a few months to more than a year after publication. Most journals provide free access to full text in PMC within a year of publication.

NLM has digitized the earlier print issues of many of the PMC journals in order to provide online access to the complete run of issues of these journals. PM C has material dating back to mid- to- late- -1800 s or early 1900 s for some journals.

The number of journals that deposits their articles in PMC falls into one of three categories:

1. For several hundred journals, PMC has the complete contents of each issue, starting with the first issue. For the older journals in this group, the back issues of a journal (generally, anything prior to the late 1990s) are available as digitized (scanned) copies of the original print journal.

2. For a smaller group of journals, PMC has complete issues and volumes for recent years, but not for all the early years of the journal.

3. For still other journals, PMC does not contain any complete issues, just a selection of articles, e.g. just those that are the result of $\mathrm{NIH}$-funded research, or those that the journal has published as open access articles.

In all three categories, PMC contains a journal's final published version of the respective articles. The PM C journal list includes information about what content is available from each journal, as well as links to that content.

In addition to the articles from these journals, PM C contains author manuscripts of selected articles from several thousand other journals. These manuscripts are accessible via a PM C search or a link from the corresponding PubM ed abstract.

\section{ELSEVIER: THE HOST OF DATABASES}

Elsevier, the modern publishing company, was founded in 1880 (Fig. 8). ${ }^{19-22}$ It has evolved from a small Dutch publishing house devoted to classical scholarship into an international multimedia publishing company with over 20,000 products for educational and professional science and health care communities worldwide. Elsevier takes its name from the original House of Elzevir, a Dutch family publishing house founded in 1580.

Elsevier's history reflects a series of collaborations in the effort to advance science and health. These publishing collaborations with a group of scientific visionaries- ranging from J ules V erne to Stephen W. H awking - -created the foundation of scientific and medical publishing.

The efforts of the men and women dedicated to disseminating and using scientific and medical knowledge have been equally critical - -the editors, printers, librarians, nurses, doctors, engineers, information specialists and business people at the center of scientific and health publishing.

Relationships with other great science publishers, such as North Holland, Pergamon, Mosby, W B Saunders, Churchill Livingstone and A cademic Press have also been integral to our success. These are just a few of the companies that are now part of the Elsevier family, bringing with them rich histories of their own. As the company moves forward, our founding motto remains apt: NonSolus - -N ot alone.

As the world's leading provider of science and health information, Elsevier serves more than 30 million scientists, 


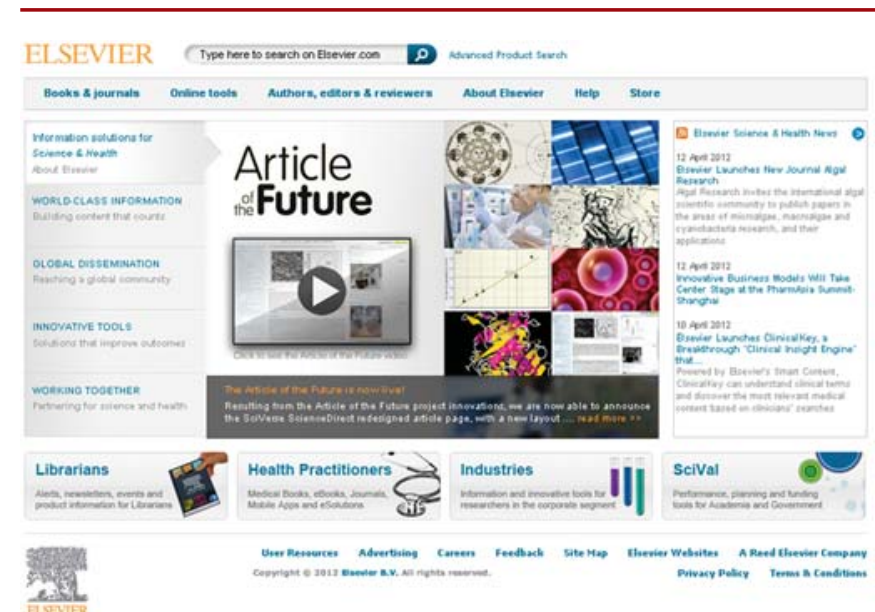

Fig. 8: Source: http://www.elsevier.com/wps/find/ intro.cws_home/ataglance. Accessed April 12, 2012

students and health and information professionals worldwide.

\section{EXCERPTA MEDICA/EMBASE}

With over 24 million indexed records and more than 7,600 currently indexed peer-reviewed journals, Embase is a highly versatile, multipurpose and up to date database covering the most important international biomedical literature from 1947 to the present day (Fig. 9). ${ }^{19,20}$ All MEDLINE records produced by the NLM are included, as well over 5 million records not covered on M EDLINE.

Core strengths of E mbase include coverage and in-depth indexing of the drug-related and clinical literature, with a particular focus on comprehensive indexing of adverse drug reactions; emphasis on evidence-based medicine (EBM) indexing including systematic reviews and coverage and indexing of journals and articles relevant to the development and use of medical devices.

If you are searching for answers to your questions or simply need reliable, peer-review ed information on topics, such as drug development or use, toxicology, drug safety/ adverse drug reactions, clinical trials, EBM, medical devices, pharmacoeconomics, preclinical reports, basic biomedical science or regulatory affairs, then Embase is the solution you are looking for.

\section{SCOPUS}

Scopus is the largest abstract and citation database of peerreviewed literature with smart tools to track, analyze and visualize research (Fig. 10). It is designed to find the information scientists need. Quick, easy and comprehensive, Scopus provides superior support of the literature research process.

SciV erse Scopus, some facts: Contains 46 million records, $70 \%$ with abstracts; $N$ early 19,500 titles from 5000

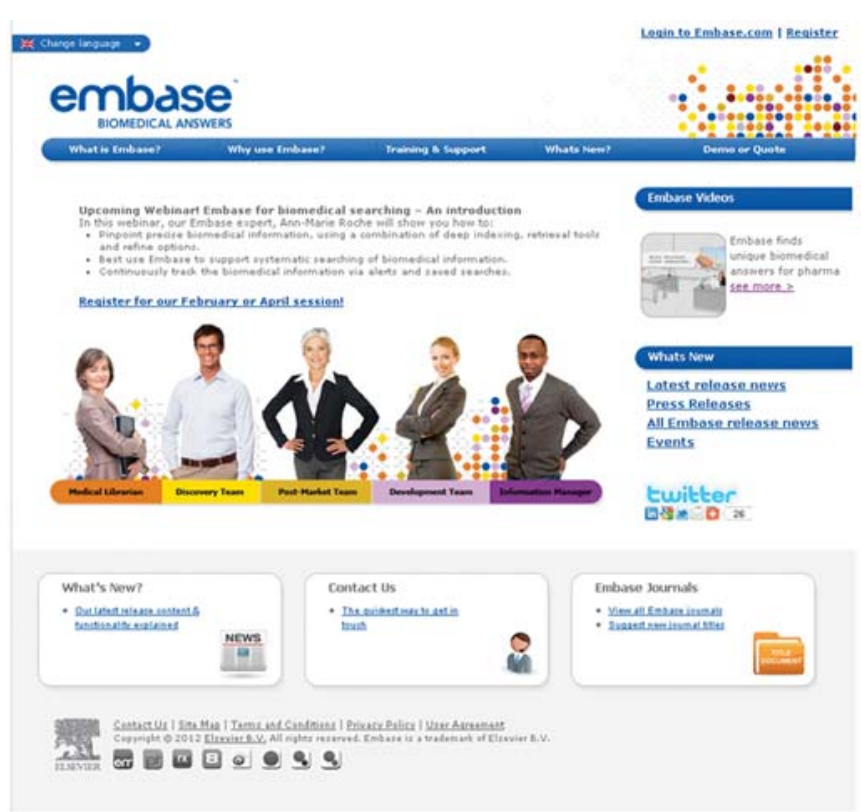

Fig. 9: Source: http://www.embase.com/. Accessed April 12, 2012

publishers worldwide; Includes over 4.6 million conference papers; Provides $100 \%$ M edline coverage; Interoperability with Engineering Village; Interoperability with Reaxys, a unique chemistry workflow solution; Offers sophisticated tools to track, analyze and visualize research.

Scopus, launched in November 2004, is the largest abstract and citation database containing both peer-reviewed research literature and quality web sources. With over 19,000 titles from more than 5000 international publishers, SciV erse Scopus offers researchers a quick, easy and comprehensive resource to support their research needs in the scientific, technical, medical and social sciences fields and, more recently, also in the arts and humanities.

SciV erse Scopus at a glance, July 2011:

a. More than 19,500 titles:18,500 peer-reviewed journals (including 1800 open access journals); 425 trade publications; 325 book series, 250 conference proceedings.

b. Fourty-six million records: 25 million records with references back to 1996 (of which 78\% include references); 21 million records pre-1996 which go back as far as 1823; 4.8 million conference papers from proceedings and journals; 'A rticles-in-Press' from over 3850 journals.

Features and functionality designed to support and improve researchers' workflow, including the following:

- A simple and intuitive interface

- Linking to full-text articles and other library resources

- Author identifier to automatically match an author's published research including the $h$-index 


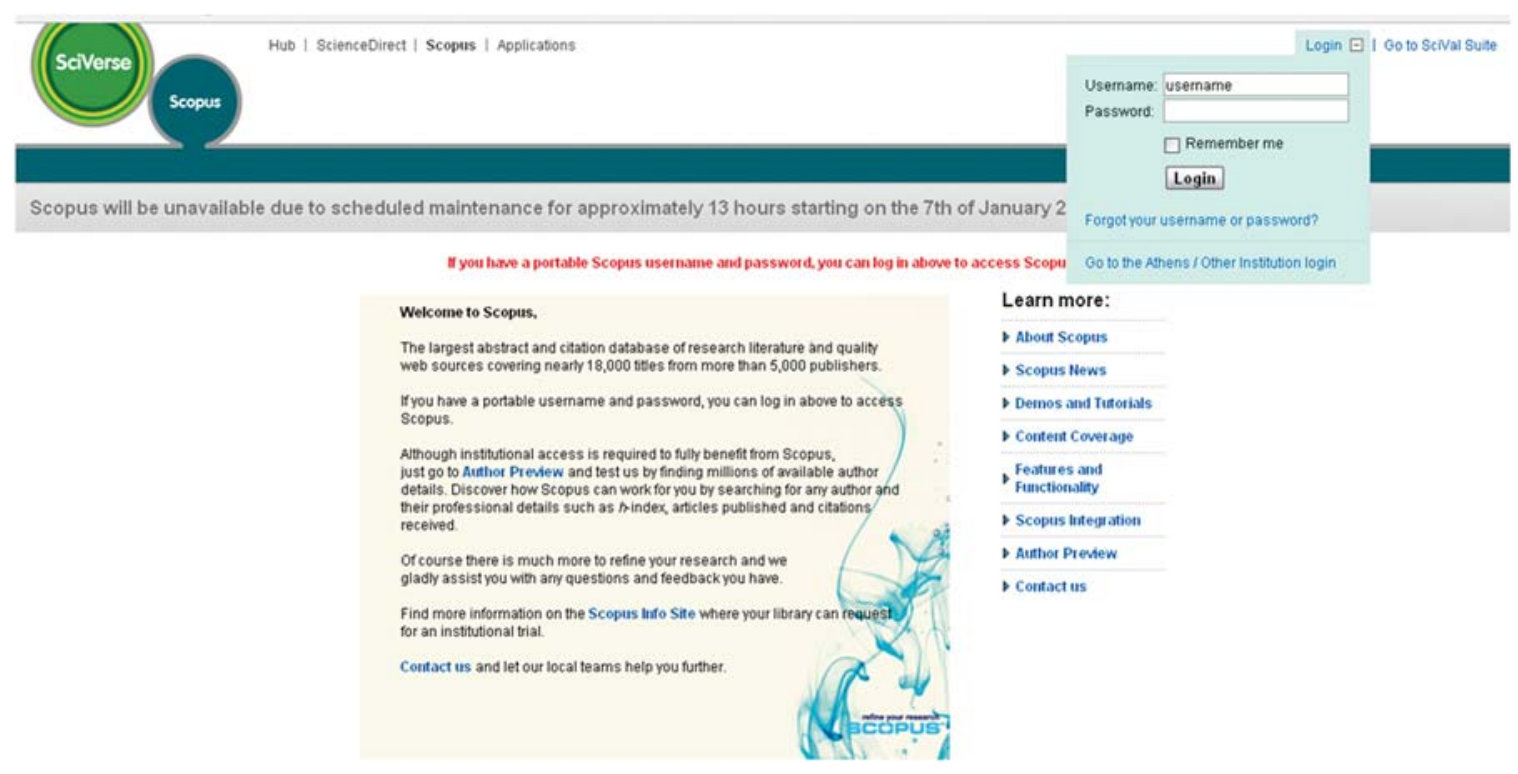

Fig. 10: Source: http://www.info.sciverse.com/scopus/scopus-in-detail/facts. Accessed April 12, 2012

- Citation tracker to simply find, check and track citations in real time

- A ffiliation identifier to automatically identify and match an organization with all its research output

- Journal analyzer provides a quick insight into journal performance

- Alerts, RSS and HTML feeds to stay up to date

- Document download manager to easily download and organize multiple full-text articles simultaneously

- Interoperability with SciV erse ScienceD irect, Reaxis and ProQuest's CSA Illumina

- Data export via bibiliographic managers, such as RefW orks, EndN ote and BibTeX.

\section{SCIRUS}

Scirus (http://www.scirus.com ) is a free web search engine developed especially for scientists, researchers and students (Fig. 11). It enables anyone searching for scientific information to pinpoint the information they need- including peer-reviewed articles, patent information, author home pages and university web sites- quickly and easily. Scirus offers both basic and advanced search options - with the advanced search, you can be more specific with what you are looking - (selecting a subject area or content source for instance) before searching.

Locating scientific information on the web is easy with Scirus because it provides the following:

- Targets scientific information only: Scirus offers an advantage over other w eb search engines because it only finds scientific content, so you do not have to wade through pages of irrelevant results to find the information you are looking for.

- Covers over 480 million science-related pages: Scirus reveals a wealth of scientific information from web sources (e.g. university sites, author homepages, company homepages, open access journals) and databases (e.g. articles from 14 scientific publishers (including Elsevier's ScienceDirect and $\mathrm{N}$ ature

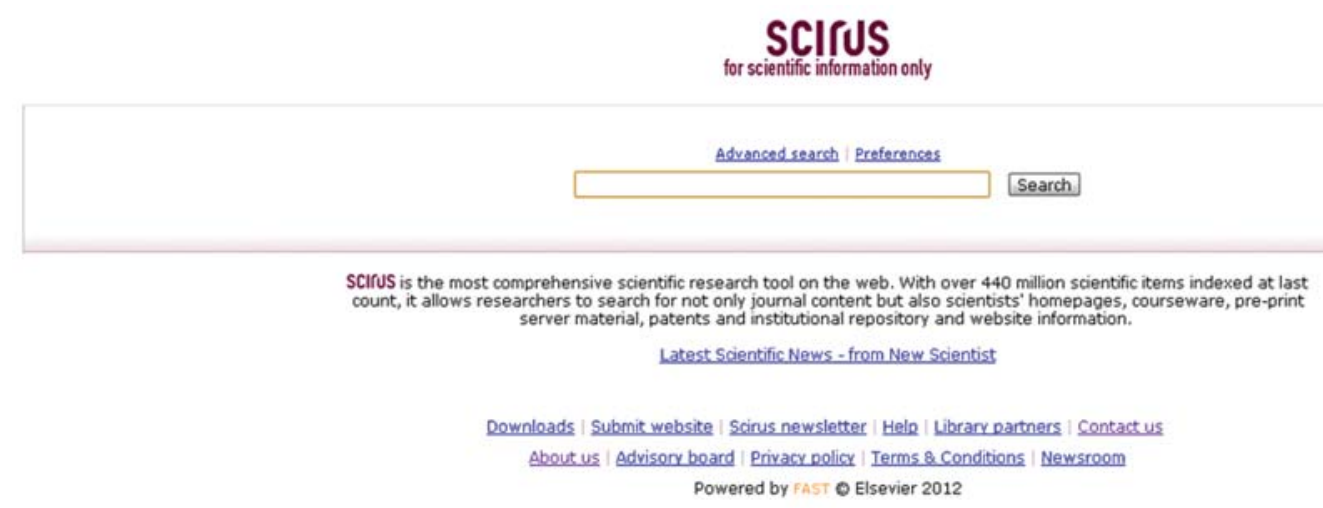

Fig. 11: Source: http://www.scirus.com/. Accesses April 12, 2012 
Publishing Group), M EDL INE abstracts, the five largest patent offices (USPTO, JPO, EPO, WIPO/PCT and UKIPO), institutional and subject repositories (e.g. A rX iv, RePEc, NASA), illuminating your research with unique sources of scientific content.

- Finds the most peer-reviewed articles: By delving deep into major databases, Scirus finds more peer-reviewed articles than any other search engine, giving you greater access to key sources of information.

- Offers unique features designed specially for scientists Scirus was specifically developed for researchers in scientific, technical and medical fields. As well as unrivalled content, Scirus has unique features and functional ities that make it easy for you to find the most relevant research information.

- Scirus has outperformed Google in usability testing and won several search engine watch awards.

\section{EBSCO}

Established in 1944, EBSCO is the world's leading information agent providing consultative services and cutting-edge technology for managing and accessing quality content, including print and e-journals, e-packages, research databases, e-books and many more (Fig. 12). ${ }^{23,24}$ Now more than ever, libraries and research organizations are looking for new ways to manage their collections more efficiently.
EBSCO Information Services has developed 'e' discovery solutions, including EBSCO A-to- $\mathrm{Z}^{\circledR}$ and LinkSource ${ }^{\circledR}$ as well as management solutions such as EBSCONET ${ }^{\circledR}$, EBSCONET ${ }^{\circledR} E R M$ Essentials ${ }^{\circledR}$ and EBSCO MARC Updates. These services offer unparalleled integration to help librarians save time and money while empowering their users.

EBSCO's leading online full-text databases include access to full-text articles from peer-reviewed journals published by the world's most prestigious academic publishers. This content supplements existing library journal subscriptions, expanding access to important publications al ready in the library's print or e-journal collection. It also provides new access to many highly-valuable full-text resources previously unavailable to users.

A s the leading database and e-B ook provider for libraries and other institutions--more than 375 full-text and secondary research databases and more than 300,000 e-Books and audiobooks available via the EBSCO host platform - -EBSCO provides unparalleled access to worldrenowned content in all subject areas including magazine and journal articles available via EBSCOhost ${ }^{\circledR}$ and HW. Wilson, e-Books and audiobooks, EBSCO's content services the research needs of tens of thousands of customers representing millions of end users from K-12 students to public library patrons, from academic, corporate and medical researchers to clinicians and governments around the world.

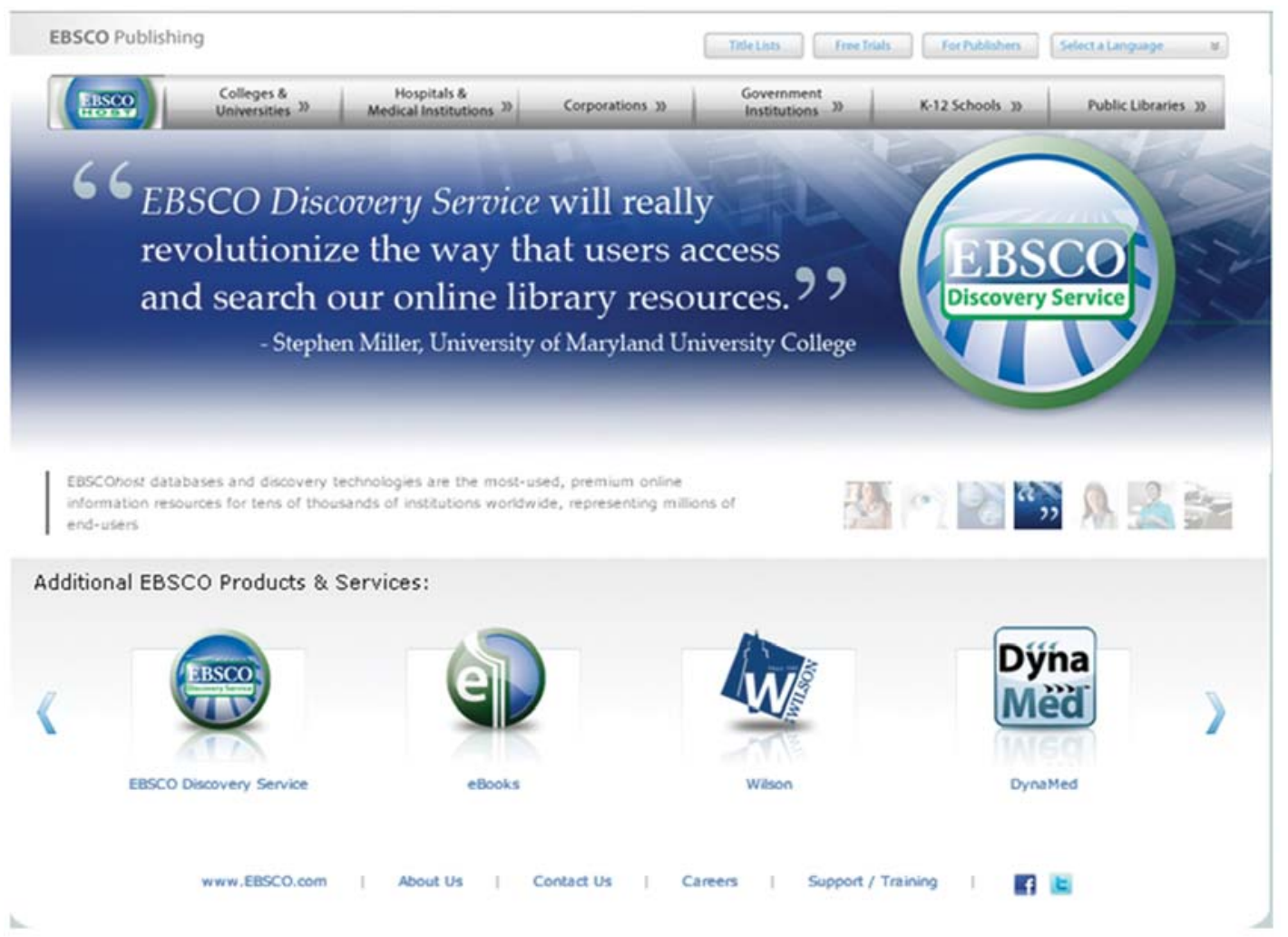

Fig. 12: Source: http://www.ebscohost.com/. Accessed April 12, 2012 
EBSCO host, stands as one of the most-used for free sites on the Internet serving upward of 100 million daily page views. EBSCOhost also powers resources, such as DynaM ed $^{\mathrm{TM}}$, an evidence-based clinical reference tool as well as other Clinical Point-of-Care R esources designed to inform the clinical workflow for hospitals and other medical institutions. EBSCO's N oveL ist division provides Readers' Advisory and Library Services Resources- -a variety of services to help empower libraries, engage readers and connect communities. Corporations and government agencies also benefit from EBSCO's content specifically in the areas of Corporate L earning, Sustainability, Chemical Hazard Information, Employee Wellness and Pharmaceutical Resources.

EBSCO is also the provider of services designed to enable libraries and other institutions to better serve students and other researchers. EBSCO Discovery Service ${ }^{\mathrm{TM}}$ provides a unified index of an institution's resources within a single, customizable search box approach allowing researchers fast, simple access to the library's full-text content plus deeper indexing and more full-text searching of a higher number of journals and magazines than any other discovery service.

B ringing together premium content that is not available anywhere else online with the innovative services libraries and other institutions need to deliver that content continues to drive EBSCO toward the next innovation.

\section{ULRICH'S PERIODICAL DIRECTORY}

Ulrich's Periodicals Directory is the standard library directory and database providing information about popular and academic magazines, scientific journals, newspapers and other serial publications (Fig. 13). ${ }^{25}$

The print version has been published since 1932, and was founded by Carolyn Ulrich, chief of the periodicals division of the New York Public Library, as Periodicals
Directory: A classified guide to a selected list of current periodicals foreign and domestic.

It is now also supplied online as Ulrichsweb, which provides web-based and Z39.50 linking to library catalogs. The online version includes over 300,000 active and current periodicals.

Coverage is international, with some emphasis on English-language publications. The information is derived from the publishers and verified by the journal. It includes the following:

- ISSN

- Title and previous titles

- Starting date, place of publication and publisher

- Cost, availability of electronic versions, subscription terms and approximate circulation as estimated by the publisher

- Subject information, searchable as subject terms or approximate Dewey classification, special features and indexing information

- Indications of whether the publication is available on open access

- Indication of whether the publication is peer-reviewed, which is taken to include professional magazines with equivalent editorial control of quality.

Earlier published by RR B owker, it moved to CSA, a fellow subsidiary of Cambridge Information Group, in 2006. Following the merger of CSA and ProQuest, Ulrich moved to ProQ uest subsidiary Serials Solutions.

\section{WHO AS A HOST OF DATABASES?}

\section{HINARI}

HINARI Program set up by W HO together with major publishers, enables developing countries to gain access to one of theworld'slargestcollections of biomedical and health literature (Fig. 14). ${ }^{26}$ M ore than 8500 journals and 7000
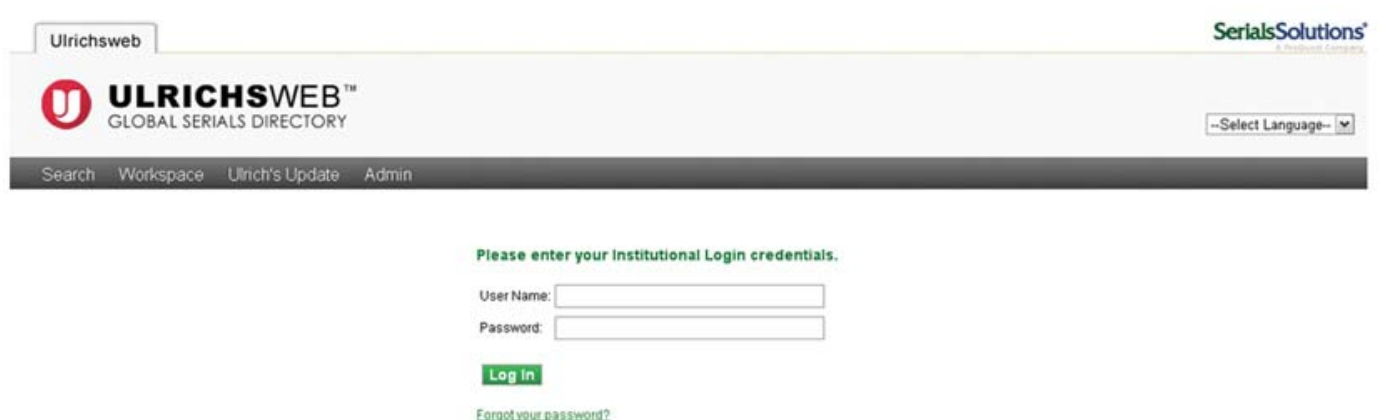

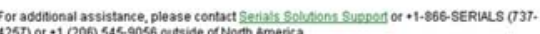

Fig. 13: Source: http://ulrichsweb.serialssolutions.com/login. Accessed April 12, 2012 


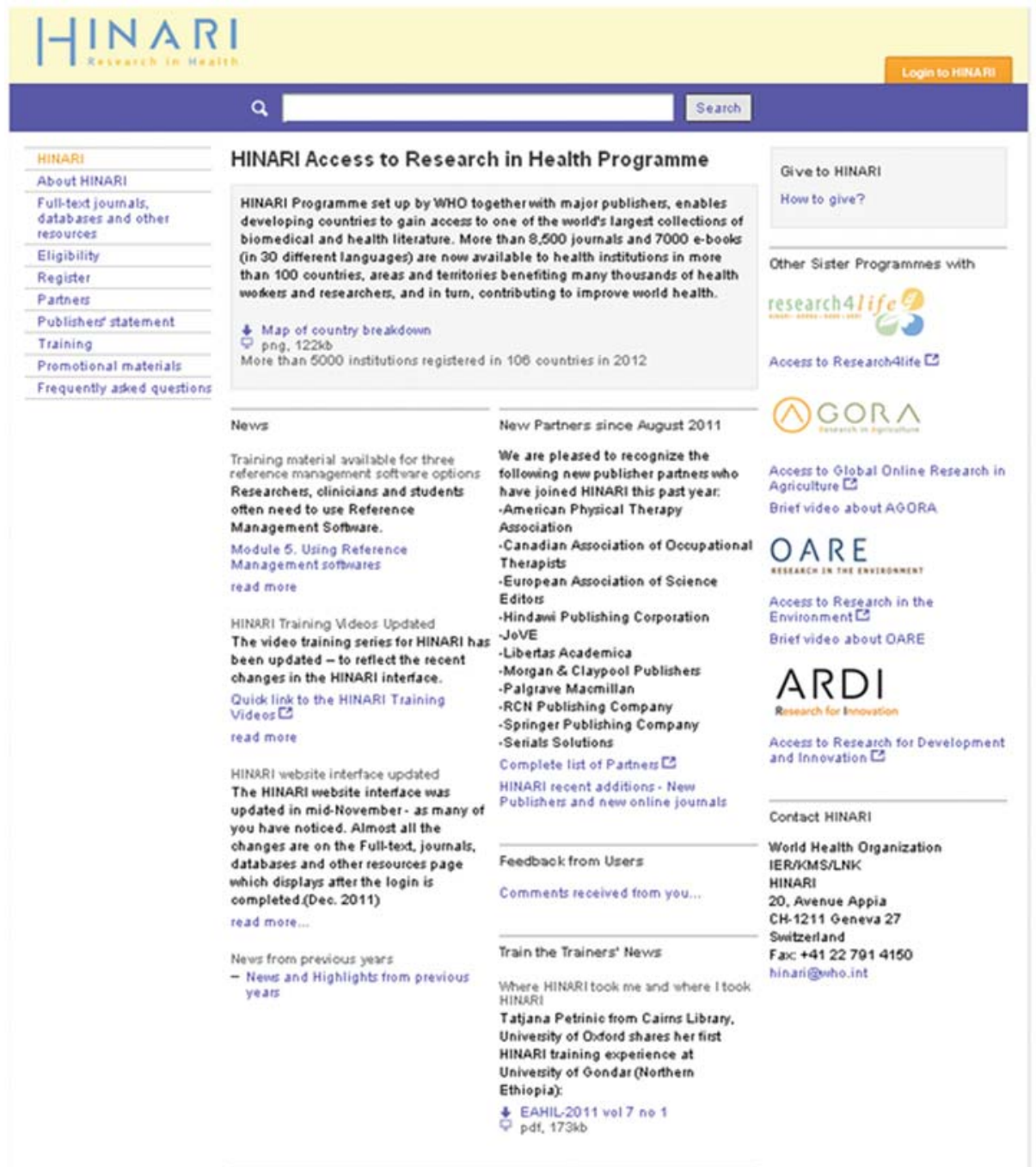

Fig. 14: Source: http://www.who.int/hinari/en/. Accessed April 12, 2012

e-books (in 30 differentlanguages) arenow availableto health institutions in more than 100 countries, areas and territories benefiting many thousands of heal th w orkers and researchers, and in turn, contributing to improve world health.

HINA RI A ccess to Research in H ealth Program provides free or very low-cost online access to the major journals in biomedical and related social sciences to local, not-for-profit institutions in developing countries.

HIN A R I was launched in J anuary 2002, with some 1500 journals from six major publishers: Blackwell, Elsevier Science, the Harcourt Worldwide STM Group, Wolters K luwer International Health and Science, Springer Verlag and J ohn Wiley, following the principles in a Statement of Intent signed in J uly 2001. Since that time, the numbers of participating publishers and of journals and other full-text resources has grown continuously. Today more than 150 publisher partners are offering more than 15,000 information resources in HINARI and many others are joining the program.

\section{GENEVA FOUNDATION FOR MEDICAL EDUCATION AND RESEARCH-GFMER}

Established in 2002, the Geneva Foundation for M edical Education and Research (GFMER) is a nonprofit organization that aims to provide health education and research training, creating programs that can be applied by developing countries and countries in economic transition (Fig. 15). ${ }^{27}$ It al so works to establish collaboration between entities from the public and private sectors. GFMER is supported by the Department of Health of the Canton of Geneva, the Department of Social A ffairs of the City of Geneva, the Faculty of M edicine of the U niversity of Geneva and the Geneva M edical A ssociation. GFMER is a WHO Collaborating $C$ enter in Education and Research in Human Reproduction.

A reas of interest are as follows:

- Medical education

- Medical research

- Training programs in research methodology, epidemiology, reproductive and sexual health. 


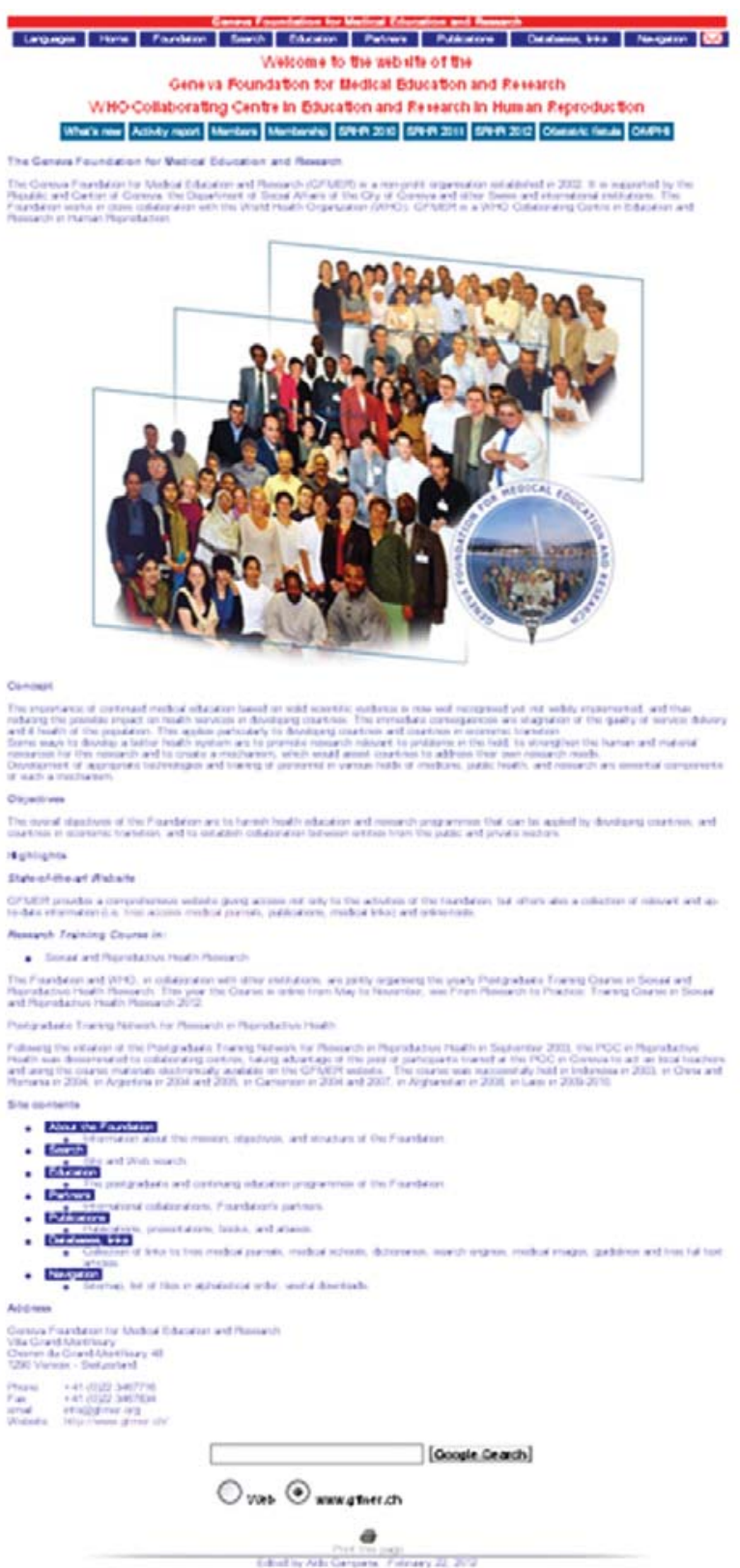

Fig. 15: Source: http://www.gfmer.ch/000_Homepage_En.htm. Accessed April 12, 2012

\section{Health-related Activities}

The activities of GFMER range from training in medical research, to research implementation, research synthesis, research management and guideline development. GFM ER runs workshops and training courses in, among other things, reproductive and sexual health research. A Postgraduate Training N etwork for Research in R eproductive $\mathrm{H}$ eal th has been established in 2003. Clinical training activities in the field of obstetric fistula are regularly held with partner institutions in resource-constrained countries.

\section{CABI}

The most comprehensive database of its kind, $C A B$ A bstracts gives researchers instant access to over 6.3 million records from 1973 onward, with over 300,000 abstracts added each year (Fig. 16). ${ }^{28}$ Its coverage of the applied life sciences includes agriculture, environment, veterinary sciences, applied economics, food science and nutrition.

$C A B I$ has excellent international coverage sets $C A B$ $A$ bstracts apart from other databases and processes all relevant publications, including less well-known and nonEnglish journals and those published by independent and learned publishers. With publications from over 116 countries in 50 languages, including English abstracts for most articles, researchers get the fullest global picture for any subject.

Global Health is the only specialist bibliographic, abstracting and indexing database dedicated to public health research and practice.

Derived from over 3500 journals, plus reports, books and conferences, Global Health contains over 1.2 million scientific records from 1973 to the present. Over 90,000

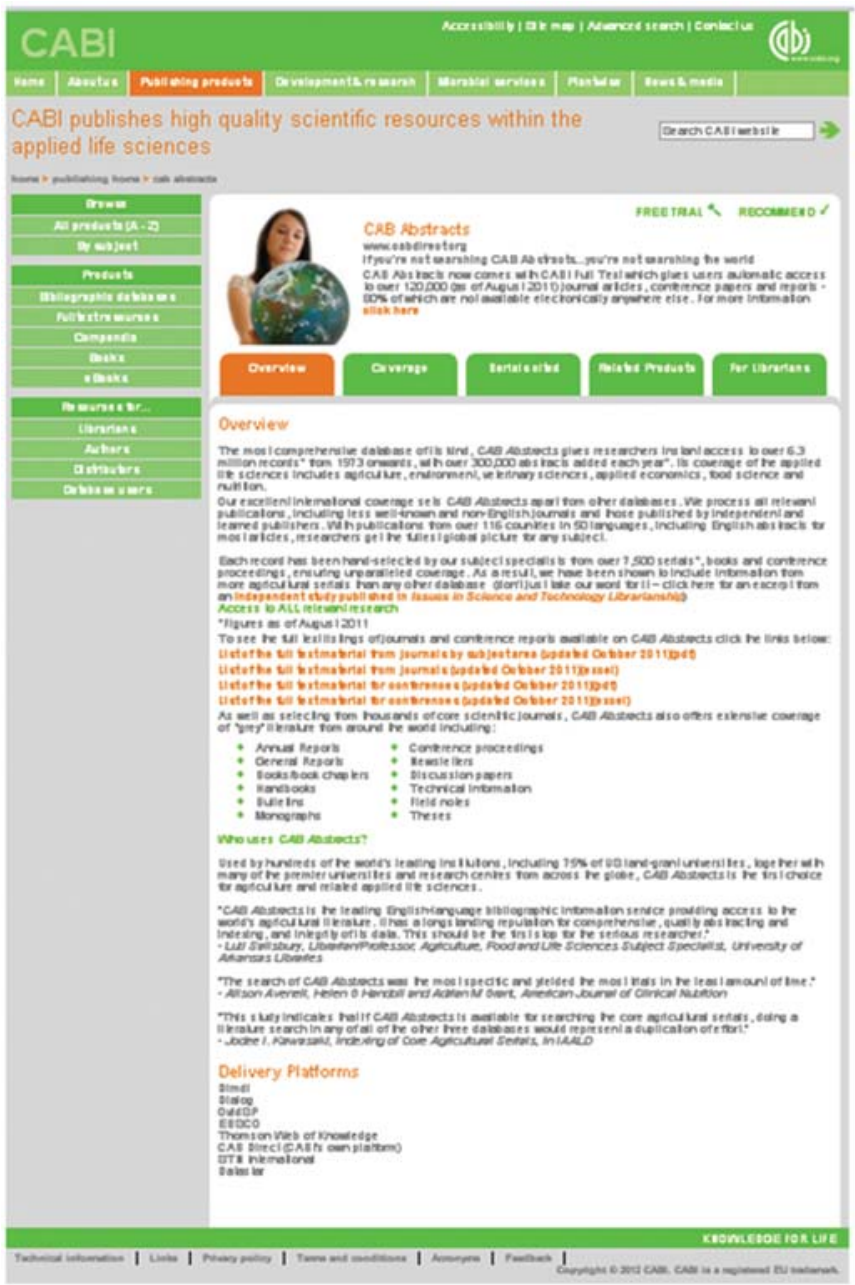

Fig. 16: Source: http://www.cabi.org/default.aspx?site= 170\&page $=1016 \&$ pid=125. Accessed April 12, 2012 
records are added each year, and over $95 \%$ of these records include an abstract. Publications from over 158 countries in 50 languages are abstracted, and all relevant non-Englishlanguage papers are translated to give access to research not available through any other database. The database's open serials policy and coverage of international and grey literature means that $40 \%$ of material contained in Global $\mathrm{Health}$ is unique to the database. Everything from proceedings, patents, theses, electronic only publications and other difficult-to-obtain sources are included. Each record has been hand-selected by subject specialists from over 7,500 serials*, books and conference proceedings, ensuring unparalleled coverage and $\mathrm{Gl}$ lobal $\mathrm{H}$ ealth database included information from more agricultural serials than any other database). As a result, we have been shown to include information from more agricultural serials than any other database (don't just take our word for it- -click here for an excerpt from an independent study published in I ssues in Science and Technology Librarianship).

\section{DIMDI-MEDICAL KNOWLEDGE ONLINE}

High-quality information for all health care areas: DIM DI is the publisher of official medical classifications, such as ICD-10-GM and OPS (German procedure classification) and maintains medical terminologies, thesauri, nomenclatures and catalogs (e.g. MeSH, UMDNS, Alpha-ID, LOINC, OID) that are important for health telematics and other applications (Fig. 17). ${ }^{29}$

DIMDI develops and operates database-supported information systems for drugs and medical devices and is responsible for a program of heal th technology assessment (HTA ). The information systems are amended by many medical databases which you can search for articles and facts throughout medicine.

\section{Health Technology Assessment}

- Describes the systematic evaluation of health-relevant procedures and methods (vaccinations, medical treatments, preventative measures, etc.);

- Examines the effectiveness, safety and economic viability of a health intervention, as well as its social, ethical, legal and organizational effects;

- Serves as the basis for decisions in the health system, e.g. in policy or in terms of treatment by a doctor.

The German A gency of Heal th Technology A ssessment (DAHTA) of the German Institute of Medical Documentation and Information (DIM DI) publishes HTA reports. These cover different topics in the area of
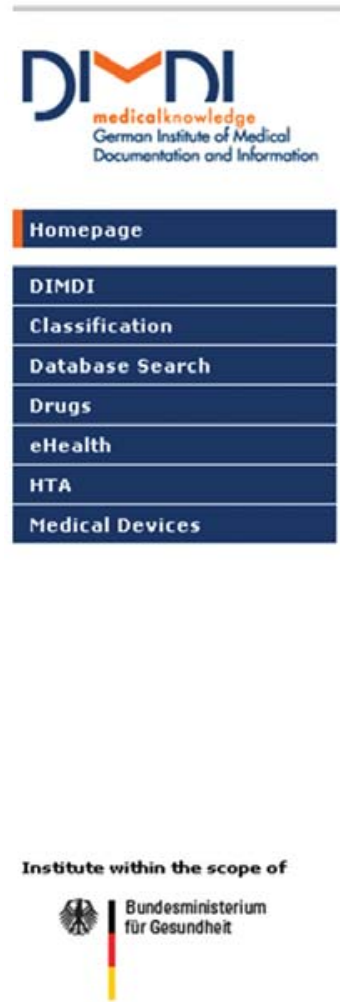

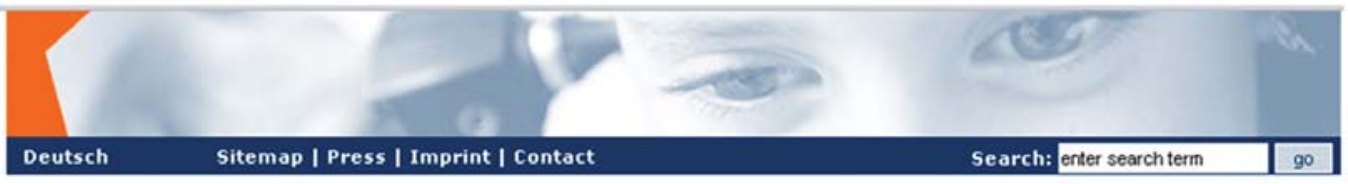

Your position: Homepage

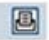

\section{DIMDI - Medical Knowledge Online}

High quality information for all health care areas: DIMDI is the publisher of official medical classifications such aS ICD-10-GM and OPS (German procedure classification) and maintains medical terminologies, thesauri, nomenclatures and catalogues (e.g. MeSH, UMDNS, Alpha-ID, LOINC, OID) that are important for health telematics and other applications.

DIMDI develops and operates database-supported information systems for drugs and medical devices and is responsible for a programme of health technology assessment (HTA). The information systems are amended by many medical databases which you can search for articles and facts throughout medicine.

\section{DIMDI News}

- DAHTA takes over the INAHTA Secretariat

- Databases: MEDLINE Reload 2012

- Database search: Prices 2012

- Databases: MEDLINE annual adaptation phase 2012

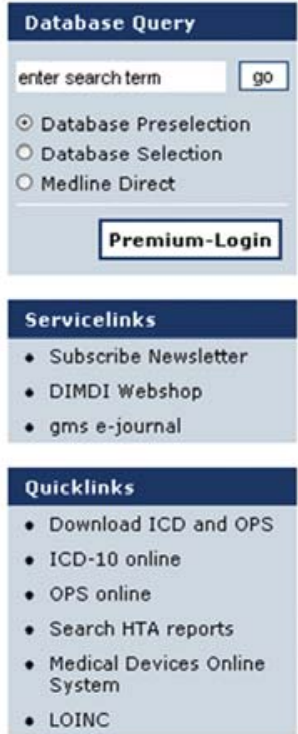

Fig. 17: Source: http://www.dimdi.de/static/en/index.html. Accessed April 12, 2012 
prevention, diagnosis, therapy, rehabilitation, nursing and methodology.

\section{RUSSIAN ACADEMY OF SCIENCES AS A HOST OF VINITI}

\section{VINITI Database of Russian Academy of Sciences}

For many years Russia has had an excellent track record for world-class scientific research conducted in research institutes under the umbrella of the A cademy of Sciences of the USSR (now the Russian A cademy of Sciences- RAS) (Fig. 18). ${ }^{30}$ Today there are about 400 research institutes under the auspice of the RAS, among them the All Russian Institute for Scientific and Technical Information (VINITI) occupies a special place as a leading agency in information processing domain.

Due to V IN ITI's mission to process all literature relating to basic and applied science published in the Russian language, its staff has a different approach for the selection of domestic and foreign journals. Editors performing journal evaluation have an educational background in various foreign languages and in library science. They also have to consult editors with an educational background in a specified field of science, if a new journal could be useful for JA (journal abstracts) on a specific discipline (as an example, for processing of J A on Physics or J A on Genetics or JA on Medicine, etc.). Due to nonexistence of the special information agency on medical sciences, VINITI took the responsibility to fill the gap and to collect and process literature on medical science since 1998.

VINITI offers the largest DataBank (DBn) in Russia via web server (http://www.viniti.ru ), with back-year data available to 1981. The total number of records is about 30 million; annual addition to $\mathrm{DB} n$ is about 1 million records. VINITI has a special group that performs bibliographic control of records. On the VINITI web server (www.viniti.ru) the DEM 0 database for demonstration is available. The search is available 24 hours a day, 7 days a week. There are approximately 1,000 requests per day.

VINITI developed its own classification scheme (Rubricator) for universal coverage on subject categories on natural and technical disciplines reflected in the V IN ITI J ournal A bstract. The Rubricator of V INITI is based on the deepening of the State Classification (Rubricator) of $S \& T$ literature (SRSTI) up to level nine--according to a need of specific area of industry. Rubricator contains: Subject heading in English and Russian languages; list of keywords indicating the frequency of their use based on the 5 years file of databases and experts' evaluation; links of subject headings to other classifications.

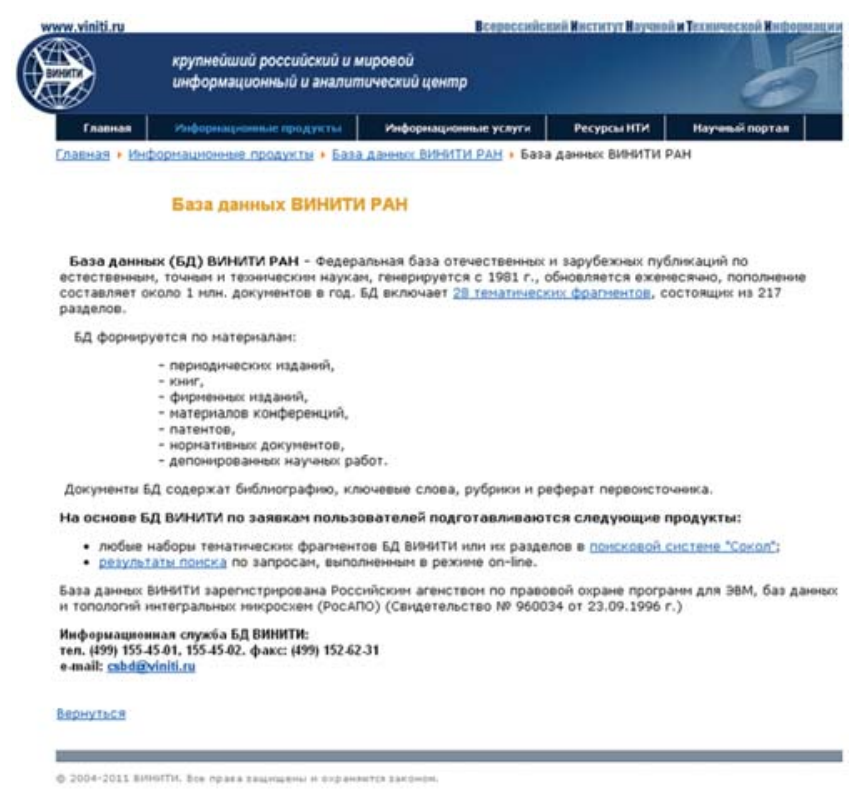

Fig. 18: Source: http://www2.viniti.ru/index.php?option= com_content\&task=view\&id=23\&ltemid=52. Accessed April 12, 2012

\section{GESDAV/ScopeMed}

ScopeM ed is a free of charge online journal/A rticle management system that can enable all of the operations of the editorial functions of a journal (Fig. 19). ${ }^{31}$ It is also known as open access indexing and online manuscript submission, review and tracking system. ScopeM ed is supported by GESDA V, a nonprofit foundation conerning education, health, social help and contribution between alumni of Gulhane M edical faculty.

A dvantages of ScopeM ed are as follows:

- Open/Free access for peer-reviewed medical journals;

- Online submission of manuscripts;

- A utomatic production of PDF file of submitted manuscripts for reviewers;

- Online review of articles;

- Editors could manage articles online;

- Scopem ed also provide a static web page for journals that using Scopemed article management system (sample: Sample J ournal W eb Page);

- Basic rules for using ScopeM ed.

\section{GOOGLE SCHOLAR}

Google Scholar is a freely accessible web search engine that indexes the full text of scholarly literature across an array of publishing formats and disciplines (Fig. 20). ${ }^{32}$ Released in beta in November 2004, the Google Scholar index includes most peer-reviewed online journals of Europe and A merica's largest scholarly publishers, plus scholarly books other nonpeer-reviewed journals. It is similar in function to the freely available Scirus from Elsevier, 


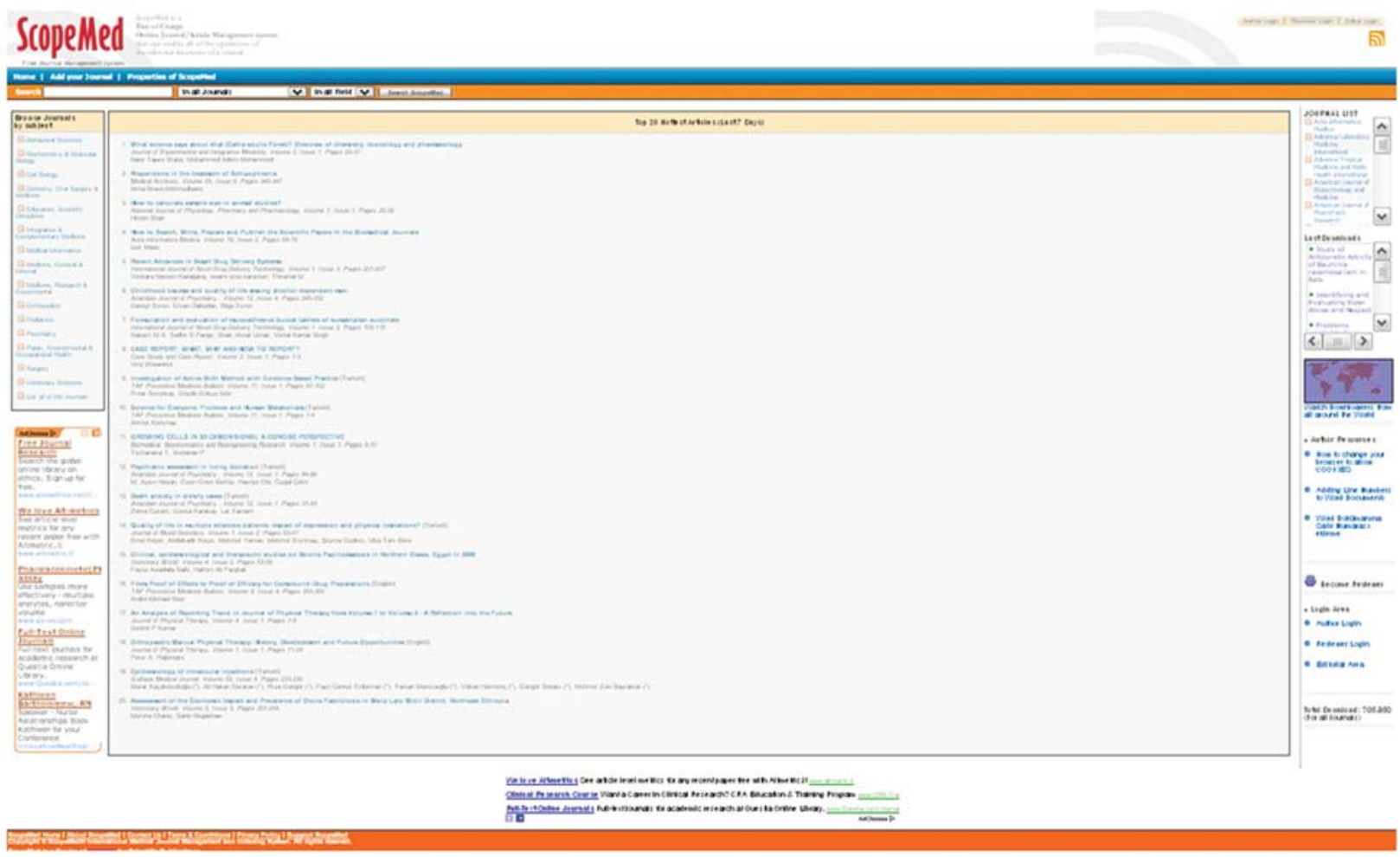

Fig. 19: Source: http://www.scopemed.org/index.php?page=about. Accessed April 12, 2012

\section{Google \\ scholar}

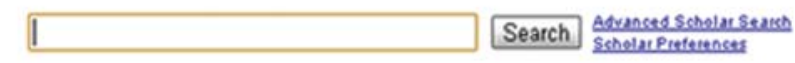

- Articles ( $\square$ include patents) O Legal opinions and journals

Stand on the shoulders of giants

About Google Scholar - About Google - My Citations

exo11 boogle

Fig. 20: Source: http://scholar.google.com/. Accessed April 12, 2012

CiteSeerX and getCITED. It is also similar to the subscription-based tools, Elsevier's Scopus and Thomson ISI's W oS . Its advertizing words - -'Stand on the shoulders of giants' - -are a nod to the scholars who have contributed to their fields over the centuries, providing the foundation for new intellectual achievements.

Google Scholar allows users to search for digital or physical copies of articles, whether online or in libraries. 'Scholarly' searches will appear using the references from 'full-text journal articles, technical reports, preprints, theses, books and other documents, including selected web pages that are deemed to be 'scholarly'. Google Scholar is as easy to use as with the regular Google web search, especially with the hel pfulness of the 'advanced search' option, which can automatically narrow search results to a specific journal or article. U sing its 'group of' feature, it shows the available links to journal articles. In the 2005 version, this feature provided a link to both subscriptions- access versions of an article and to free full-text versions of articles; for most of 2006, it provided links to only the publishers' versions. Since December 2006, it has provided links to both published versions and major open access repositories, but still does not cover those posted on individual faculty web pages access to such self-archived nonsubscription versions is now provided by a link to Google, where one can find such open access articles.

\section{INDEX COPERNICUS}

The aim of this web-based communication platform is to offer a set of essential tools for global scientists netw orking and international research collaboration, providing scientists with the following:

- Integration of different sources of information: Literature, grants and patents and the personalized delivery thereof based on scientists profiles;

- Effective communication and exchange of information between scientists;

- Worldwide scientists networking based on research profiles; 


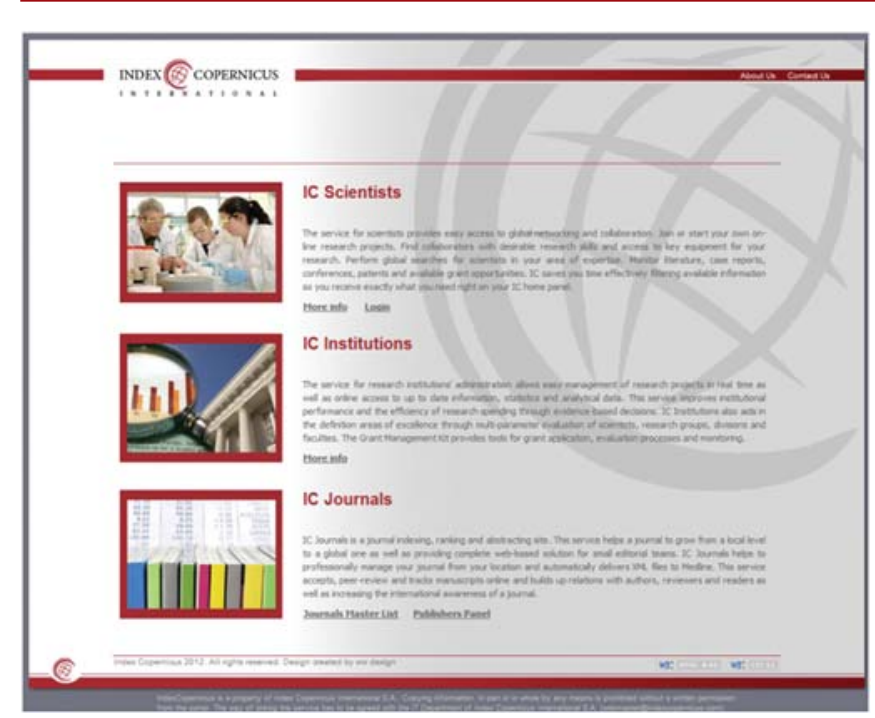

Fig. 21: Source: http://indexcopernicus.com/. Accessed April 12, 2012

- Web-based infrastructure for management of multicenter research projects;

- Notification of scientific/professional job vacancies on a personal basis;

- Multiparameter career evaluation system which analyses research potential, innovation index, teaching potential and administration experience.

Easily join or start your own online research projects, find collaborators with desirable research skills and access to key equipment for your research or search worldwide for scientists operating in your area of expertize and compare your professional career with those of others. It monitors literature, case reports, conferences, patents and available grant opportunities. IC saves your time effectively, filtering available information so you receive exactly what you need right on your IC home panel (Fig. 21). ${ }^{33}$

\section{ISLAMIC WORLD SCIENCE CITATION CENTER}

Islamic world science citation center (ISC) is basically a system which provides citation analysis based on scientometrics theories. Its first ignition was in 2000 based on a research project called 'Persian Journal Citation Reports' conducted by $M$ ehrad and $M$ aghsoudi, researchers of R egional Information Science and Technology in Shiraz (Fig. 22). ${ }^{34}$ The center is located in Shiraz, it aims at promoting technical and scientific cooperation among M uslim scientists and M uslim countries worldwide. ISC benefits from theoretical scientometrics and its aims are served through a fully automated citation analysis. The result would be the ability of measuring the scientific impact of publications. One of ISC's major advantages over other powerful citation analysis tools, such as ISI or Scopus is its

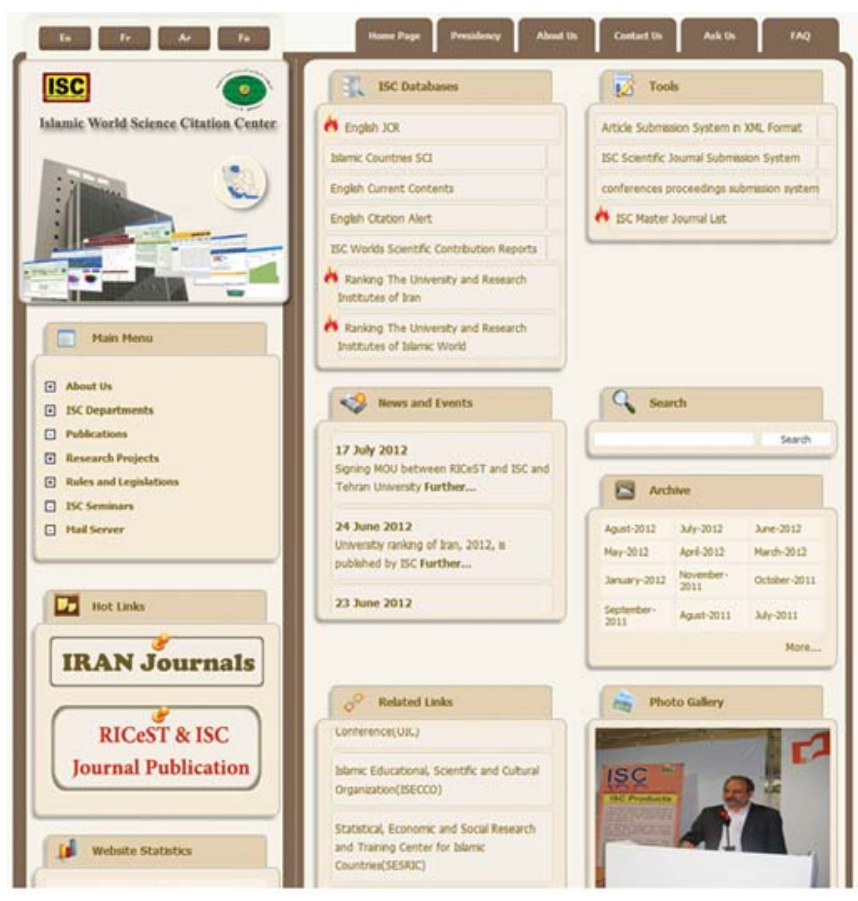

Fig. 22: Source: http://www.isc.gov.ir/. Accessed April 12, 2012

encompassing mission regarding national languages. Other citation tools and databases do focus on English-language journals, but there is no doubt that a considerable amount of scientific production is prepared in the national language of the authors in non-E nglish language countries. Thus, ISC gives them a chance to disseminate their scientific work through an international channel. A wide range of scientific disciplines, including medicine, are covered in ISC databases. There are more than 550 titles currently indexed in ISC which deal with the subject and among them about 200 of these titles have gained I mpact F actor (IF) according to the automatic citation analysis performed on them. In total, sum of 134 English journals in the field of medicine is currently indexed in ISC databases.

Scientific and research journals which are peer-reviewed are selected to be indexed in ISC. These journals are normally published by universities and research centers. B ased on this policy, since 2008 the database has received a wealth of worldwide collection. A wide range of tools have been developed within the ISC databases: ISC Science Citation Database, which is the main product of ISC and through its simple and advanced search interface, it delivers the full text of papers along with their references and received citations; ISC English journal Citation Reports (EJCR), which offers some statistics regarding journals IF and also their immediacy index; ISC Current Contents, which delivers the Contents of each journal received recently, by existed several ways in order to access the contents of this database, among which one can mention 
alphabetical index, search box and also subject list of journals; ISC Citation Current A wareness, which services, based on ISC Science Citation Index, possibility to experts define their scientific profile and based on their interests they are notified upon any new record that has been added to the database. This system al so has this peculiar ability to notify its user upon any new citation received by a paper of interest. Finally, ISC worlds Scientific Contribution Report is unique tool for analyzing scientific contribution of countries worldwide, based on any desired geographical region, from continents to countries and from regions to different International organization member states, even based on indicators such as economic classification, or being an OIC country, OECD country, or even OPEC country (the reports are readily available based on any required or suitable chart type in different subject fields). Persian Journal Citation Reports, Persian Essential Science Indicator, Persian Highly-Cited Proceedings Database and University Rankings of Islamic Countries are among other remarkable products of ISC. For a better interaction with ISC databases and speeding the whole process up, a submission system is newly launched. Journal submission systems in general do have some benefits and added values. Reducing the work load, standardizing the process, making the information coherent and homogeneous, possibility of further automatic analysis/manipulation, processable outputs and a more facilitated interaction are among their named advantages. For about 3 years, ISC benefited from a semiautomatic journal submission system. But now with an ever increasing workload and a good knowledge base for migrating from this semiautomatic submission system, the X M L -based journal submission system is launched. The system currently has both E nglish and Persian interface and its $A$ rabic version is currently under construction.

Due to its web-based features, ISC products are available worldwide and due to its functions, ISI and Scopus are interested in further cooperation with ISC. On the contrary, because of its encompassing nature regarding different languages, ISC products pave the way for achieving a unique database which provides value-added knowledge about scientific contribution of different Islamic Countries along with the full text al their respected journals in their native language. Furthermore, because of the evaluation of universities carried out by ISC more and more organizations are interested in indexing their journals in ISC databases. In other words, ISC has provided a robust foundation for projecting scientific journals, scientists and researchers' views on one side and assessing universities and research centers scientific performance on the other side. There is no doubt that ISC still needs more cooperation from Islamic scientific journals, scientists, universities and research centers worldwide, but it is for sure one of the most important facilitators of knowledge cooperation among M uslim countries.

\section{CONCLUSION}

M ost of medical journals now has its electronic version, available over public netw orks. A Ithough there are parallel printed and electronic versions, and one other form need not to be simultaneously published. Electronic version of a journal can be published a few weeks before the printed form and must not has identical content. Electronic form of the journals may have an extension that does not contain a printed form, such as animation, 3D display, etc., or may have available full text, mostly in PDF or XLM format, or just the contents or a summary. A ccess to a full text is usually not free and can be achieved only if the institution (library or host) enters into an agreement on access. $M$ any medical journals, however, provide free access for some articles, or after a certain time (after 6 months or a year) to complete content. The search for such journals provides the network archive as High W ire Press, F ree M edical J ournals.com. It is necessary to allocate PubM ed and PMC, the first public digital archives unlimited collect journals of available medical literature, which operates in the system of the N L M in B ethesda (USA). There are so-called online medical journals published only in electronic form. It could be searched over online databases. In this paper, authors shortly described about 30 databases and short instructions on how to make access and search the published papers in indexed medical journals.

\section{REFERENCES}

1. M asic I, Ridjanovic Z, Pandza H, M asic Z. M edical Informatics. A vicena, Sarajevo 2010:279-334.

2. M asic I, M ilinovic K. On-line Biomedical D atabases-The best source for quick search of the scientific information in biomedicine. Acta Inform M ed 2012;20(2):72-84.

3. M asic I. How to search, write, prepare and publish the scientific papers in the biomedical journals. Acta Inform Med 2011;19(2):68-79.

4. M arkusova V . All Russian Institute for Scientific and Technical Information (VINITI) of the R ussian A cademy of Sciences. A cta Inform M ed 2012 J un;20(2):113-17.

5. M ehrad I, A rastoopoor S. I slamic W orld Citation Center (ISC): Evaluating scholarly journals based on citation analysis. A cta Inform M ed 2012; 20(1):132-38

6. M asic I. Ethical aspects and dilemmas of preparing, writing and publishing of the scientific papers in the biomedical journals. A cta Inform M ed 2012 Sep; 20(3):141-47.

7. Gasparyan Y A, Ayvazyan L, K itas DG. Biomedical journal editing: Elements of success. CMJ 2011;52:423-28.

8. M arusic $A$. Importance of ethical publishing in developing countries. A cta Inform M ed 2012;20(1):4. 
9. O'D owd A. Peer-review system needs thorough evaluation. M Ps hear. BMJ 2011;342:d3046.

10. International Committee of M edical J ournals Editors. U niform requirements for manuscript submitted to biomedical journals: Writing and editing for biomedical publication. (Updated October 2008). A vailable at http://www.icmje.org/. A ccessed A pril 12, 2012

11. Council of Science Editors. CSE's W hite Paper on Promoting Integrity in Scientific) ournal Publications. Editorial policy committee (2005-2006). A vailable at http://www. CouncilScienceE ditors.org. Accessed A pril 12, 2012.

12. World Association of M edical Editors. WAME recommendations on Publication Ethics and Policies for M edical J ournals. A vailable at http://www.wame.org/resources/ethics-resources. Accessed A pril 12, 2012.

13. Committee On Publication Ethics. COPE. Code of Conduct and Best Practice Guidelines for J ournal E ditors. A vailable at http:// publicationethics.org/resources/guidelines.

14. A vailable at: http://thomsonreuters.com/products_services/ science/science_products/a-z/current_contents/. A ccessed A pril 12, 2012.

15. A vailableat: http://wokinfo.com/about/whatitis/. A ccessed A pril 12,2012

16. A vailable at: http://thomsonreuters.com/products_services/ science/science_products/a-z/web_of_science/. A ccessed A pril 12, 2012.

17. A vailable at: http://www.nlm.nih.gov/pubs/factsheets/nlm.html. Accessed A pril 12, 2012.

18. A vailable at: http://www.nlm.nih.gov/pubs/factsheets/ medline.html. A ccessed A pril 12, 2012.

19. A vailable at: http://www.ncbi.nlm.nih.gov/pmc/about/intro/. Accessed A pril 12, 2012.

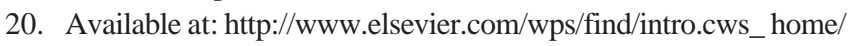
ataglance. A ccessed A pril 12, 2012.

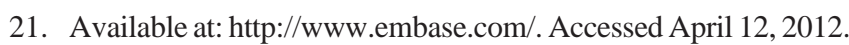

22. A vailable at: http://www.info.sciverse.com/scopus/scopus-indetail/facts. A ccessed A pril 12, 2012.

23. A vailable at: http://www.el sevier.com/wps/find/electronic productdescription.cws_home/672920/description\#description. Accessed A pril 12, 2012.

24. A vailable at: http://www.ebscohost.com/about-us. A ccessed A pril 12, 2012.

25. A vailable at: http://ul richsweb.serialssolutions.com/login. Accessed A pril 12, 2012.

26. A vailable at: http://www.who.int/hinari/about/en/. A ccessed A pril 12, 2012

27. Available at: http://www.gfmer.ch/000_Homepage_En.htm. Accessed A pril 12, 2012.

28. A vailable at: http://www.cabi.org/default.aspx? site $=170$ \& page $=1016 \&$ pid=125. A ccessed A pril 12, 2012.

29. A vailable at: http://www.dimdi.de/static/en/index.html. Accessed A pril 12, 2012.

30. A vailable at: http://www2.viniti.ru/index.php?option=com_content $\&$ task=view\& id=23\&Itemid=52. A ccessed A pril 12, 2012.

31. A vailable at: http://www.scopemed.org/index.php?page=about. Accessed A pril 12, 2012.

32. A vailable at: http://scholar.google.com/. Accessed A pril 12, 2012.

33. A vailable at: http://indexcopernicus.com/. A ccessed A pril 12, 2012.

34. A vailable at: http://www.isc.gov.ir/. A ccessed A pril 12, 2012.

\section{ABOUT THE AUTHOR}

\section{Izet Masic}

Professor, Department of Family Medicine, Faculty of M edicine University of Sarajevo, B osnia and Herzegovina

Correspondence Address: A sima Ferhatovica 17, 71000 Sarajevo Bosniaand Herzegovina,e-mail: imasic@lol.ba, izetmasic@gmail.com 